\title{
Paraffin Phase Change Material for Maintaining Temperature Stability of IceCube Type of CubeSats in LEO
}

\author{
Michael K. Choi* \\ NASA Goddard Space Flight Center, Greenbelt, MD 20771
}

\begin{abstract}
The MLA and IFA of the instrument on the IceCube require a $20^{\circ} \mathrm{C}$ temperature and a thermal stability of $\pm 1^{\circ} \mathrm{C}$. The thermal environment of the ISS orbit for the IceCube is very unstable due to solar $\beta$ angles in the $-75^{\circ}$ to $+75^{\circ}$ range. Additionally the instrument is powered off in every eclipse to conserve electrical power. These two factors cause thermal instability to the MLA and IFA. This paper presents a thermal design of using mini paraffin PCM packs to meet the thermal requirements of these instrument components. With a $31 \mathrm{~g}$ mass plus a $30 \%$ margin of n-hexadecane, the MLA and IFA are powered on for 32.3 minutes in sunlight at $\mathrm{a}^{\circ} \beta$ angle to melt the paraffin. The powered-on time increases to 38 minutes at a $75^{\circ}(+$ or -$) \beta$ angle. When the MLA and IFA are powered off, the paraffin freezes.
\end{abstract}



\section{Introduction}

TCECUBE is a 3U CubeSat mission at NASA Goddard Space Flight Center. It is scheduled to be launched from a nano-rack on the International Space Station (ISS) in 2016. It will be a free flyer in the ISS orbit. Fig. 1 shows a CubeSat launched from the ISS. The primary scientific goal of the IceCube mission is to measure cloud ice from space. The mission life is six months. Fig. 2 is a schematic of the IceCube. The sun sensor, which is located at the spacecraft's -Y side, always points along the solar vector. The IceCube spins about the Y-axis at 3 minutes per

\footnotetext{
${ }^{*}$ Senior Aerospace Engineer, Heat Transfer, AIAA Associate Fellow.
} 
revolution. The instrument consists of four components: Mixer LO Assembly (MLA), Intermediate Frequency Assembly (IFA), Receiver Interface Card (RIC) and Power Distribution Unit (PDU). It is accommodated by the upper (+Z) $13 \mathrm{~cm} \mathrm{x} 10 \mathrm{~cm} \times 10 \mathrm{~cm}$ volume. Fig. 3 shows the instrument engineering test unit (ETU). The spacecraft (S/C) bus internal components are accommodated by the remaining volume. There are two deployable solar array wings. Each has two panels hinged together, with solar cells on the $-\mathrm{Y}$ side. The outboard panel of each wing also has solar cells on the $+Y$ side, which serve as backup for off-nominal scenario when sunlight impinges the $-Y$ side. The panels are made of FR4. The stowed solar array mount panels on the $+\mathrm{X}$ and $-\mathrm{X}$ sides of the IceCube are also made of FR4. When the deployable solar array wings are stowed, they are hinged to the mount panels. There is a fixed $2 \mathrm{U}$ solar array panel on the $-\mathrm{Y}$ side and a fixed $1 \mathrm{U}$ solar array panel on the $-\mathrm{Z}$ side of the IceCube body. The latter serves as a backup. These panels are also made of FR4.

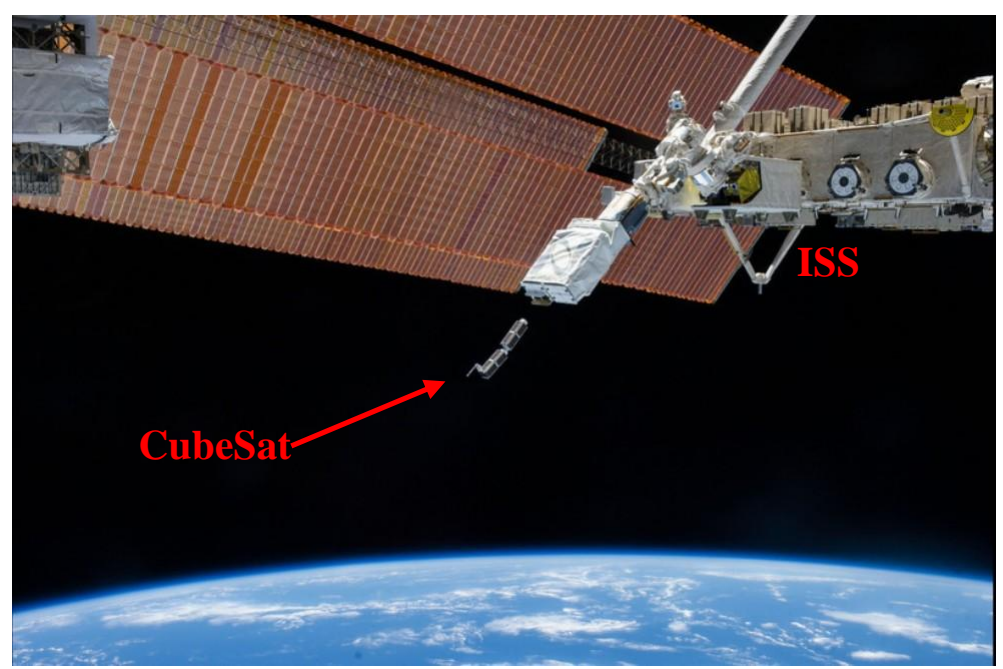

Figure 1. CubeSat Launched from the ISS (Credit: NASA).
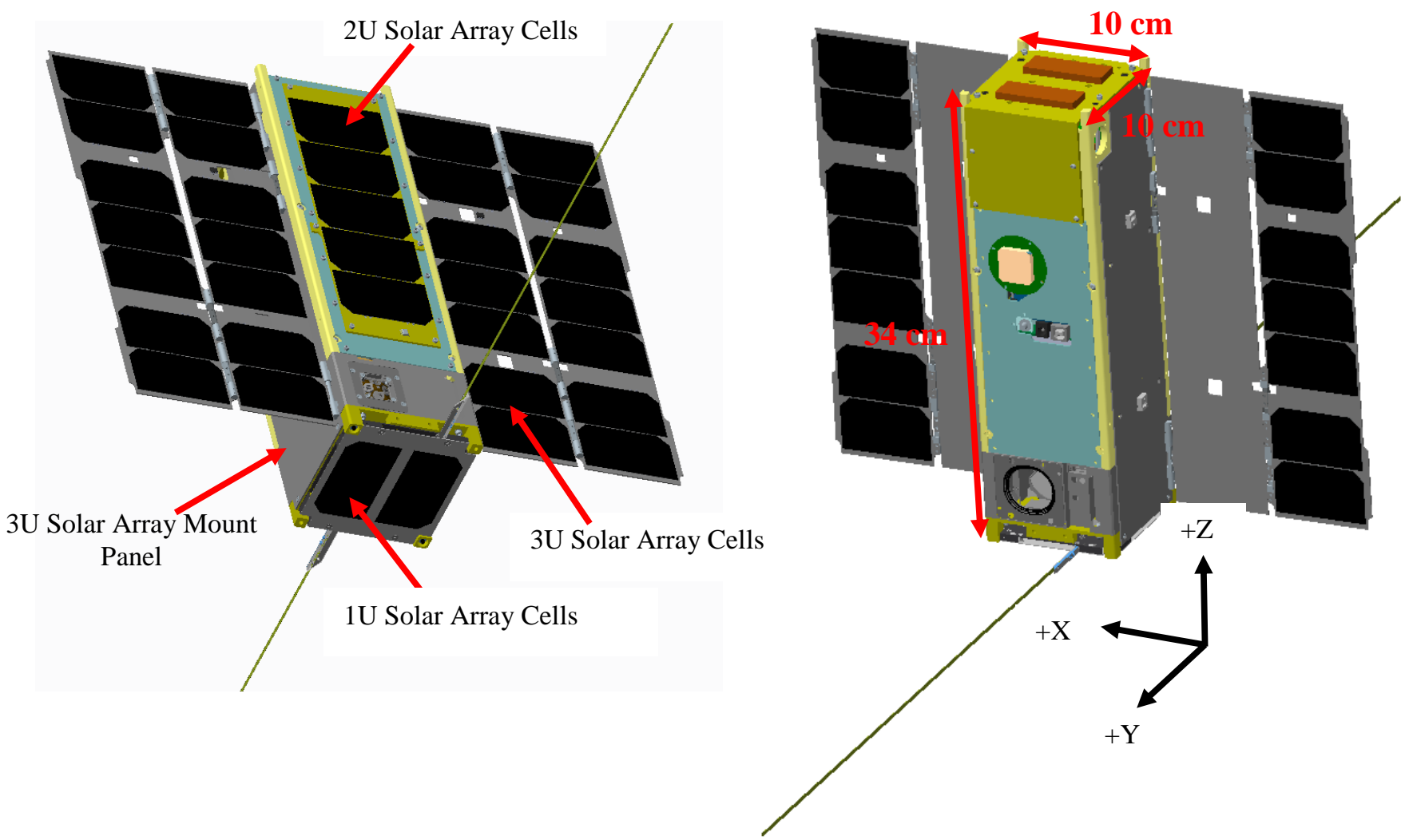

Figure 2. Schematic of IceCube. 


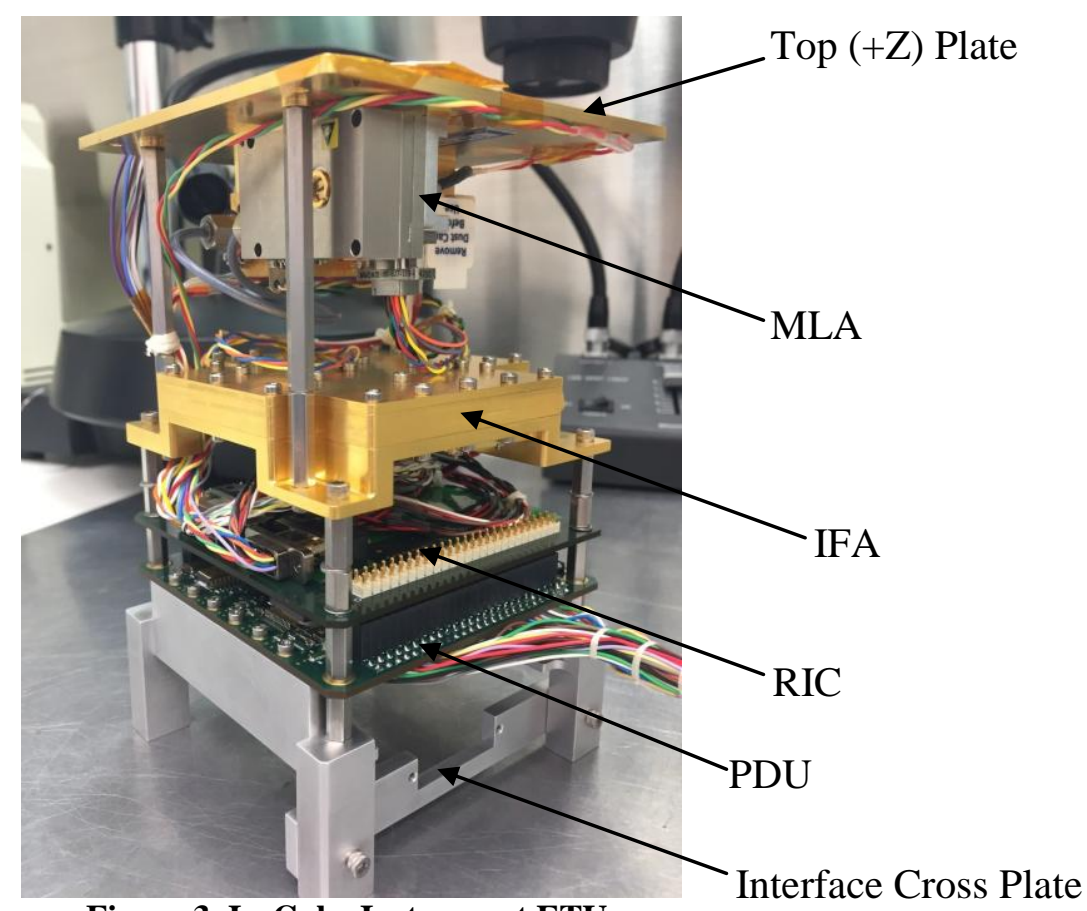

Figure 3. IceCube Instrument ETU.

\section{IceCube Thermal Requirements}

Fig. 4 shows the instrument and S/C bus components on the IceCube. Aluminum standoffs are used for stacking these components. Table 1 presents the power dissipation of the components. Table 2 presents the thermal requirements.

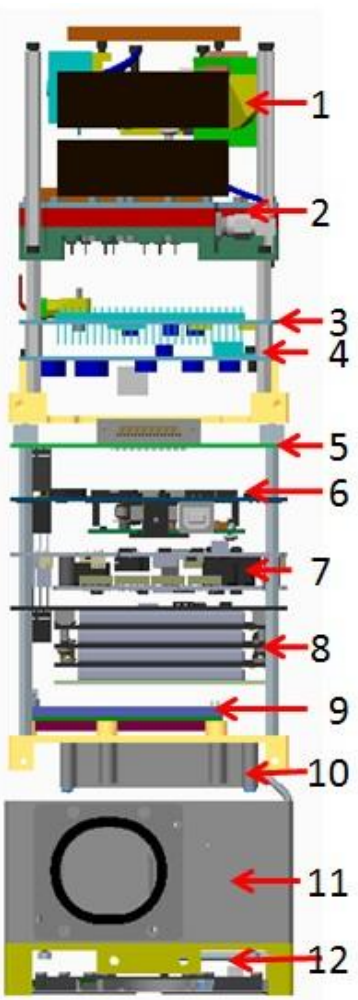

\begin{tabular}{|c|c|c|}
\hline 1 & Instrument & MLA \\
\hline 2 & Instrument & IFA \\
\hline 3 & Instrument & RIC \\
\hline 4 & Instrument & PDU \\
\hline 5 & S/C Bus & Bus Custom IC \\
\hline 6 & S/C Bus & $\begin{array}{c}\text { Pumpkin D2 Flight } \\
\text { Computer }\end{array}$ \\
\hline 7 & S/C Bus & Clyde Space EPS \\
\hline 8 & S/C Bus & Clyde Space Battery Pack \\
\hline 9 & S/C Bus & Novatel GPS Receiver \\
\hline 10 & S/C Bus & L3 Cadet Radio \\
\hline 11 & S/C Bus & BCT-XACT ADAC \\
\hline 12 & S/C Bus & ISIS UHF Antenna \\
\hline
\end{tabular}

Figure 4. Components of IceCube. 
Table 1. Power Dissipation.

\begin{tabular}{|c|c|c|c|}
\hline & & Component & Nominal (W) \\
\hline 1 & Instrument & MLA & 0.3 \\
\hline 2 & Instrument & IFA & 2.42 \\
\hline 3 & Instrument & RIC & 0.765 \\
\hline 4 & Instrument & PDU & 0.066 \\
\hline 5 & S/C Bus & Bus Custom IC & Sunlight: $2.149 ;$ eclipse: 0.188 \\
\hline 6 & S/C Bus & Pumpkin D2 Flight Computer & Sunlight: $2.086 ;$ eclipse: 0.037 \\
\hline 7 & S/C Bus & Clyde Space EPS-PDU & 1.2 \\
\hline 9 & S/C Bus & Clyde Space Battery Pack & 0.3 \\
\hline 10 & S/C Bus & Novatel GPS Receiver & 1.997 \\
\hline 11 & S/C Bus & L3 Cadet Radio & 0.1 \\
\hline 12 & S/C Bus & BCT-XACT ADAC & 0.02 \\
\hline
\end{tabular}

Table 2. Thermal Requirements.

\begin{tabular}{|c|c|c|c|c|}
\hline & Component & $\begin{array}{c}\text { Operating } \\
\text { Temperature }\left({ }^{\circ} \mathrm{C}\right)\end{array}$ & $\begin{array}{l}\text { Temperature } \\
\text { Stability }\left({ }^{\circ} \mathrm{C}\right)\end{array}$ & $\begin{array}{c}\text { Survival Temperature } \\
\left({ }^{\circ} \mathrm{C}\right)\end{array}$ \\
\hline 1 & MLA & 20 & \pm 1 & -40 to 60 \\
\hline 2 & IFA & 20 & \pm 1 & -40 to 60 \\
\hline 3 & RIC & -20 to 40 & None & -40 to 60 \\
\hline 4 & PDU & -20 to 40 & None & -40 to 60 \\
\hline 5 & Bus Custom IC & -20 to 40 & None & -40 to 60 \\
\hline 6 & Pumpkin D2 Flight Computer & -40 to 85 & None & -50 to 100 \\
\hline 7 & Clyde Space EPS & -40 to 85 & None & -50 to 100 \\
\hline 8 & Clyde Space Battery Pack & $-10 *$ to 50 & None & -40 to 60 \\
\hline 9 & Novatel GPS Receiver & -40 to 85 & None & -40 to 90 \\
\hline 10 & L3 Cadet Radio & -20 to 40 & None & -40 to 60 \\
\hline 11 & BCT-XACT ADAC & -30 to 50 & None & -40 to 60 \\
\hline 12 & ISIS UHF Antenna & -30 to 70 & None & -40 to 90 \\
\hline 13 & GPS Antenna & -40 to 85 & None & -40 to 90 \\
\hline
\end{tabular}

*Battery internal heater set point: $0^{\circ} \mathrm{C}$ on and $5^{\circ} \mathrm{C}$ off 


\section{IceCube Thermal Environment}

The IceCube orbit is the same as the ISS low Earth orbit (LEO). Its orbit parameters are a) 350 to $400 \mathrm{~km}$ altitude, b) $51.6^{\circ}$ inclination, and c) nearly circular orbit. Fig. 5 shows the solar beta ( $\beta$ ) angle and eclipse time for this orbit. Fig. 6 shows the orbit thermal model for three solar $\beta$ angles. The orbit period is 91.95 minutes. The solar $\beta$ angle is in the $-75^{\circ}$ to $+75^{\circ}$ range over a year. The eclipse time varies from 0 to 36.3 minutes, which the 30-day IceCube mission could encounter.
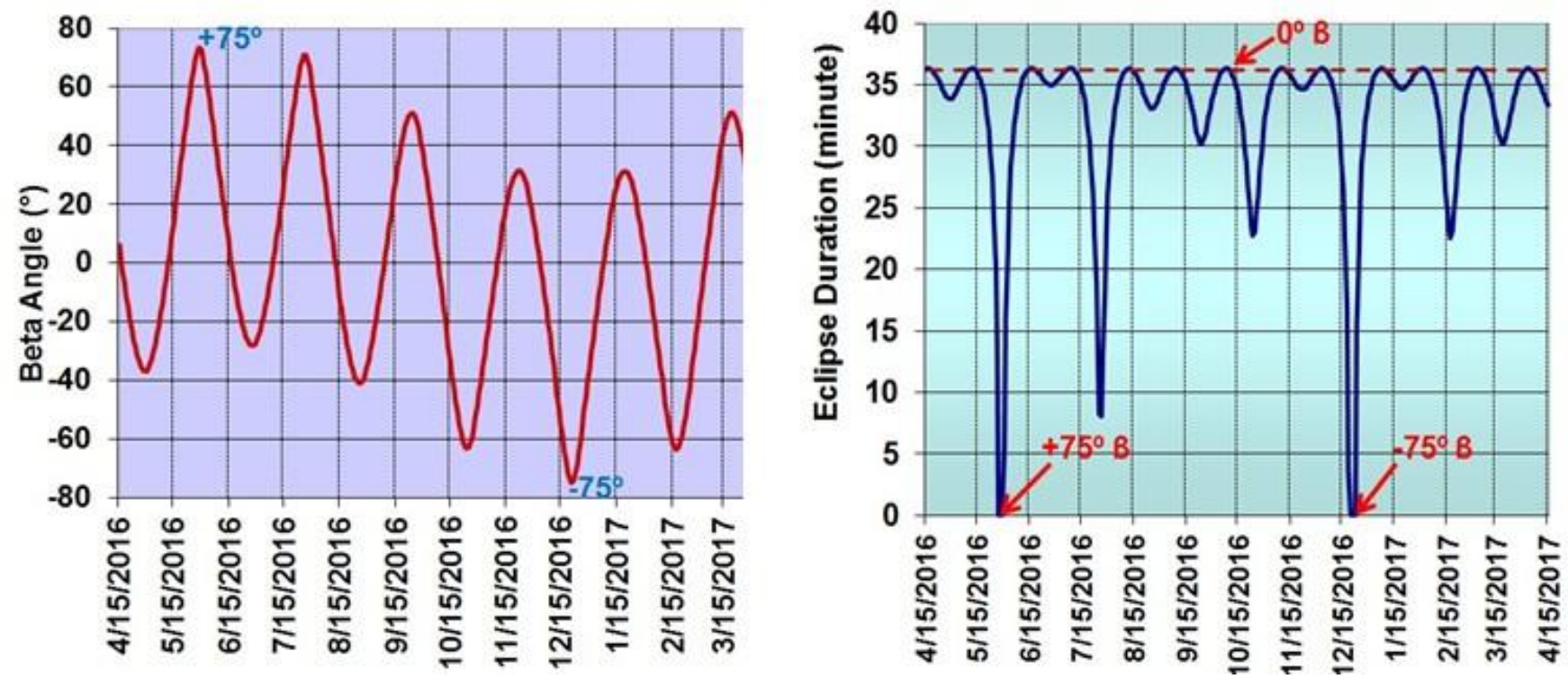

Figure 5. Solar $\beta$ Angle and Eclipse Time.
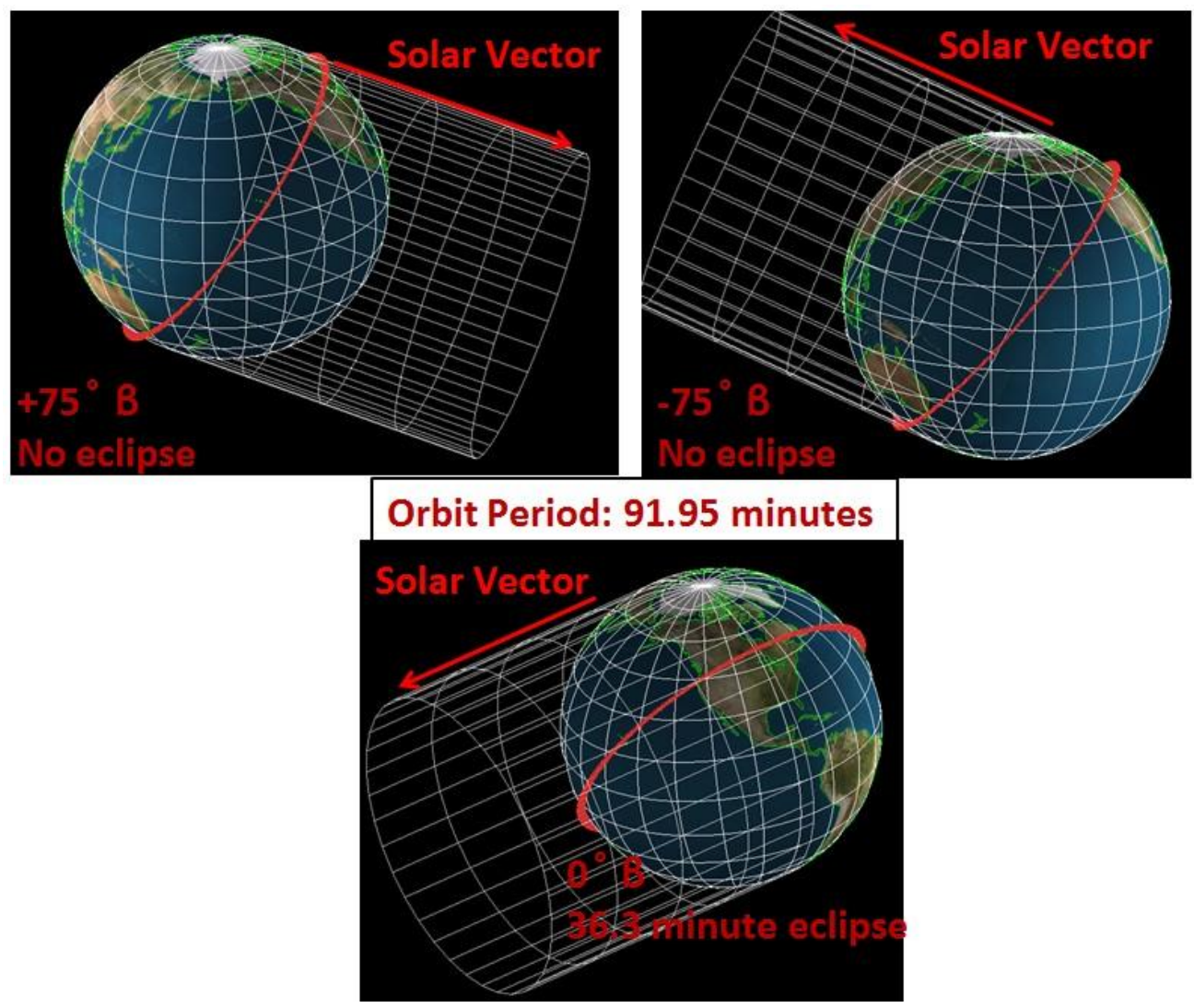

Figure 6. Orbit Thermal Model. 
To illustrate the orbit thermal environment for the IceCube, a blackbody cube of $1 \mathrm{~m} \times 1 \mathrm{~m} \times 1 \mathrm{~m}$ is used. Like the IceCube, the blackbody cube spins about the $\mathrm{Y}$-axis at 3 minutes per revolution. Fig. 7 and Fig. 8 show the environmental heat flux absorbed by each side of the blackbody cube and its equivalent sink temperature for a $0^{\circ}$ solar $\beta$ angle. They are shown in Fig. 9 and Fig. 10 for a $+75^{\circ}$ solar $\beta$ angle. These plots reveal that the ISS orbit thermal environment for the IceCube is very unstable. Additionally, to conserve electrical power, the instrument is powered off in the Earth's eclipse of each orbit. These are double penalties to the MLA and IFA thermal stability.

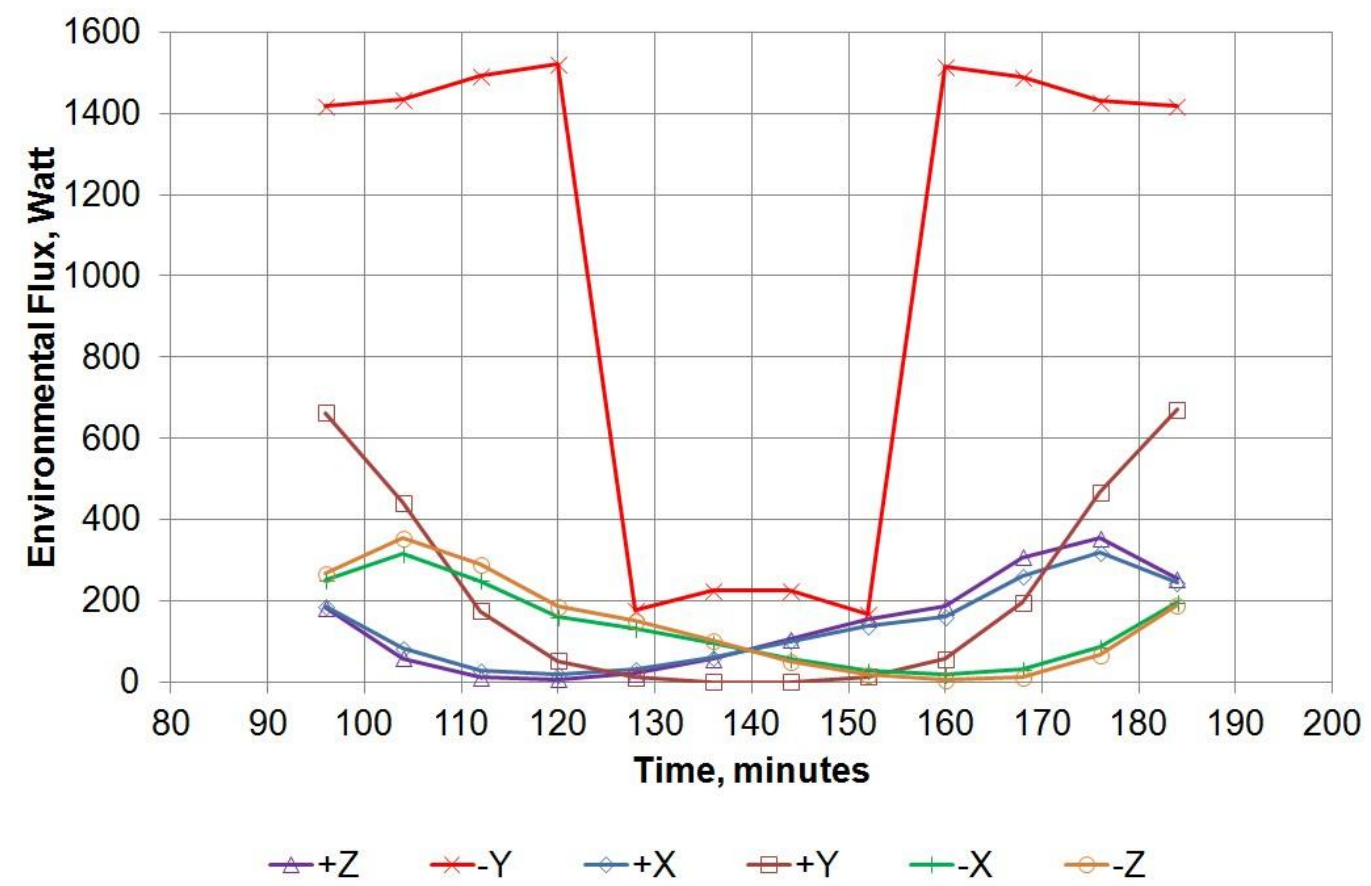

Figure 7. Environmental Heat Flux Absorbed by $1 \mathrm{~m} \times 1 \mathrm{~m} \times 1 \mathrm{~m}$ Blackbody Cube at $0^{\circ} \beta$.

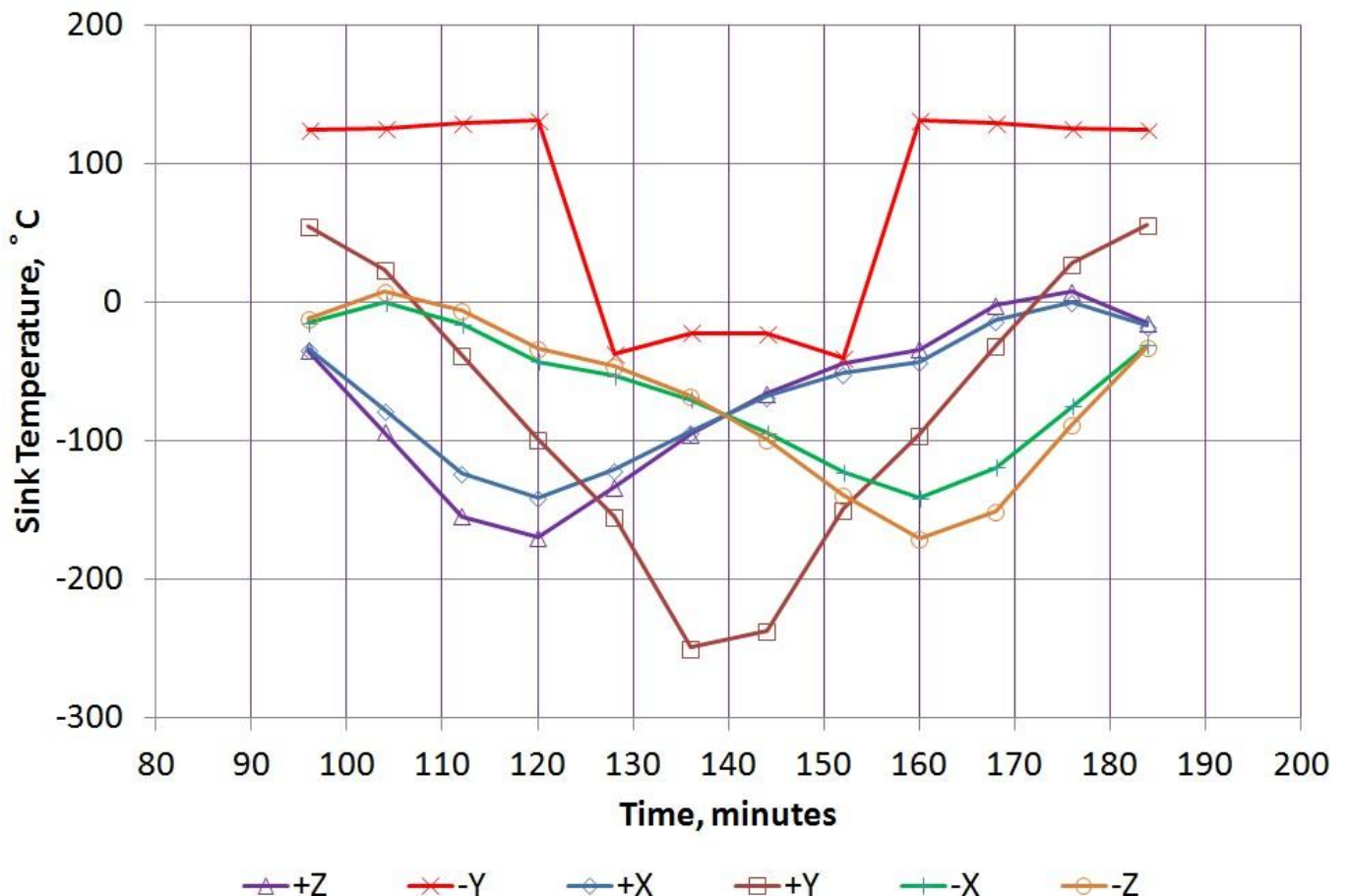

Figure 8. Equivalent Sink Temperature for $1 \mathrm{~m}$ x $1 \mathrm{~m}$ x $1 \mathrm{~m}$ Blackbody Cube at $0^{\circ} \beta$. 


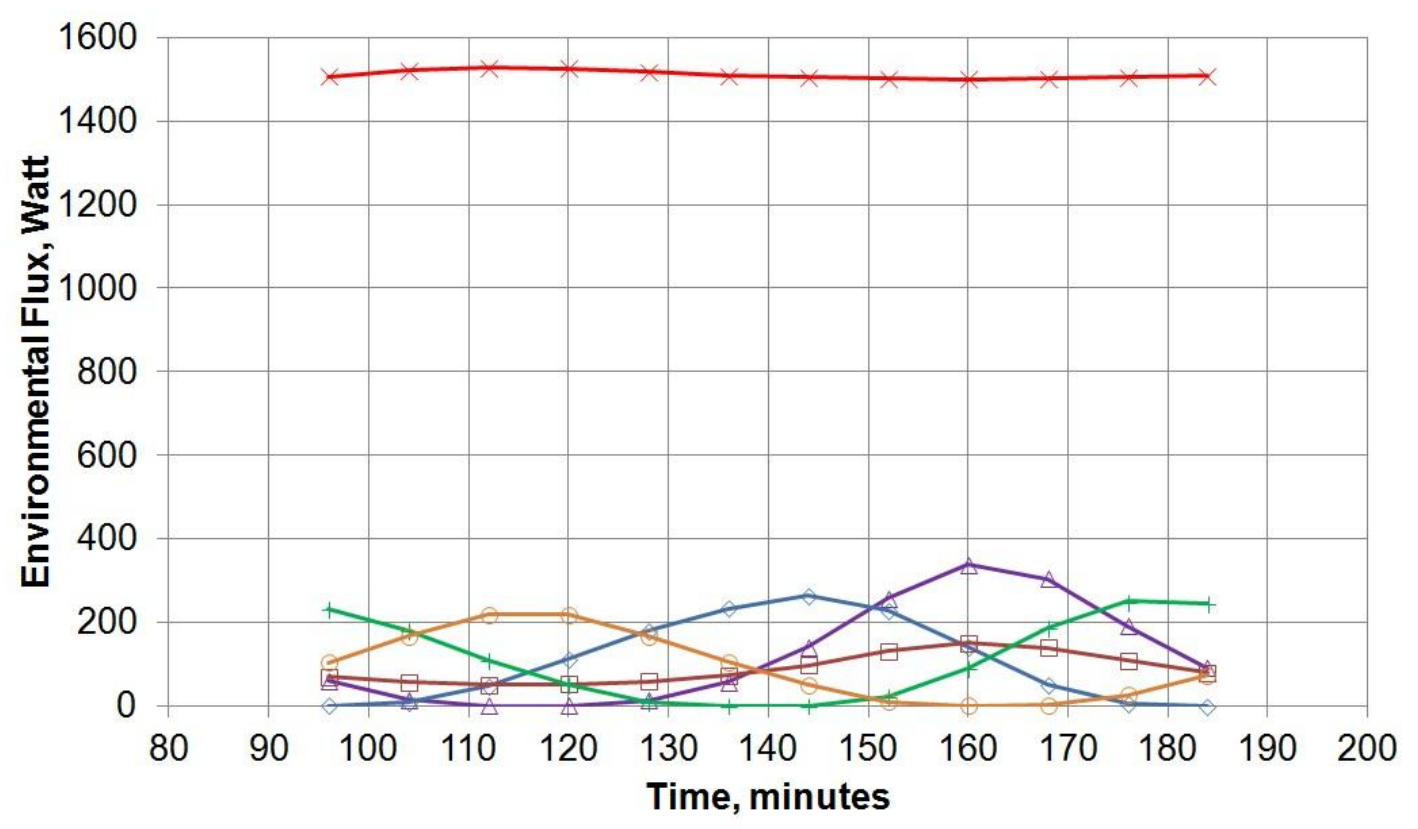

$\triangle+Z \quad *-Y \quad \smile+X \quad \square+Y \quad+-X \quad \bullet-Z$

Figure 9. Environmental Heat Flux Absorbed by $1 \mathrm{~m}$ x $1 \mathrm{~m} \times 1 \mathrm{~m}$ Blackbody Cube at $+75^{\circ} \beta$.

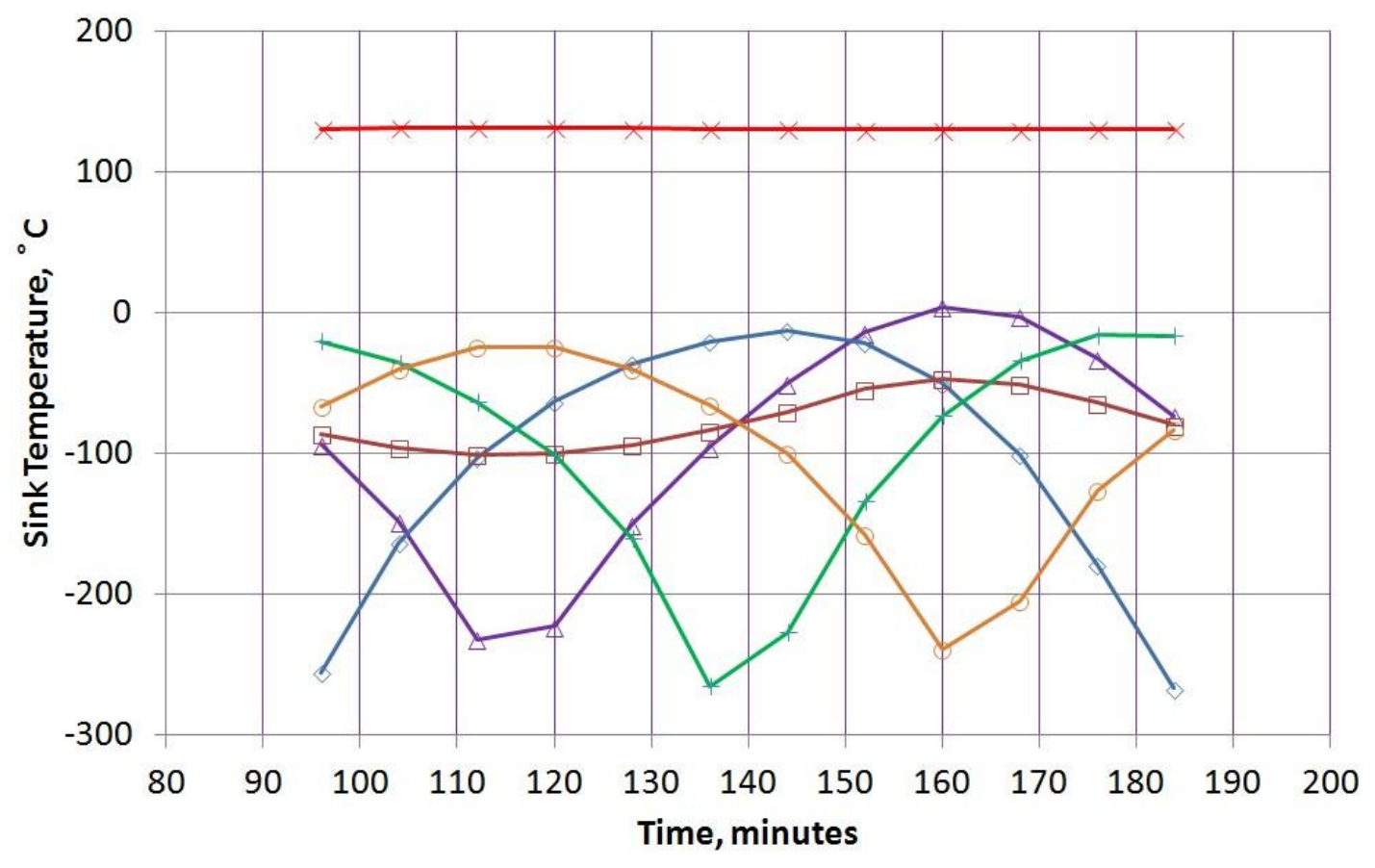

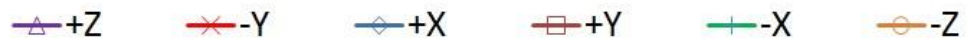

Figure 10. Equivalent Sink Temperature for $1 \mathrm{~m} \times 1 \mathrm{~m} \times 1 \mathrm{~m}$ Blackbody Cube at $+75^{\circ} \beta$. 


\section{Objective}

The objective of this paper is to present a thermal design of using mini paraffin phase change material (PCM) packs to meet the temperature and temperature stability requirements of the MLA and IFA on the IceCube.

\section{IceCube Thermal Design and Analysis}

Thermal design and analysis of the IceCube are discussed below. In this paper, emphasis is placed on using paraffin PCM to meet the temperature and temperature stability requirements of the MLA and IFA.

\section{A. Heat Capacity}

Heat capacity is important for thermal design and analysis of the IceCube because the thermal environment in the ISS orbit is strongly dependent on the solar $\beta$ angle, which is in the $-75^{\circ}$ to $+75^{\circ}$ range. The current best estimates of mass, shown in Tables 3 and 4 , are used for computing the IceCube heat capacity.

Table 3. Mass Estimates of Instrument and Spacecraft Bus Components (kg).

\begin{tabular}{|c|c|}
\hline \multicolumn{2}{|c|}{ Instrument } \\
\hline MLA & 0.145 \\
\hline IFA & 0.268 \\
\hline RIC & 0.106 \\
\hline PDU & 0.124 \\
\hline Harness & 0.045 \\
\hline S/C Bus & 0.094 \\
\hline Bus Custom Interface Card & 0.088 \\
\hline Pumpkin Flight Computer & 0.155 \\
\hline Clyde Space EPS & 0.256 \\
\hline Clyde Space Battery Pack & 0.220 \\
\hline L3 Cadet Radio & 0.030 \\
\hline Novatel GPS Receiver & 0.850 \\
\hline BCT XACT & 0.100 \\
\hline ISIS UHF Antenna & 0.020 \\
\hline GPS Antenna & \\
\hline & \\
\hline
\end{tabular}


Table 4. Mass Estimates of Structure and Solar Arrays.

\begin{tabular}{|c|c|c|}
\hline Component & Mass (kg) & Material \\
\hline Payload Interface Cross Plate & 0.090 & Al 6061 \\
\hline Bus Cross Plate & 0.058 & Al 6061 \\
\hline Side Wall on $+X$ Face & 0.157 & Al 6061 \\
\hline Side Wall on -X Face & 0.163 & Al 6061 \\
\hline Top Interface Plate & 0.121 & $\mathrm{Al} 6061$ \\
\hline Bottom Interface Plate & 0.118 & $\mathrm{Al} 6061$ \\
\hline Solar Array Interface Panel on $+X$ Face & 0.142 & FR4 (2.4 mm thick) \\
\hline Solar Array Interface Panel on -X Face & 0.142 & FR4 (2.4 mm thick) \\
\hline Back Panel on + Y Face & 0.062 & Al 6061 \\
\hline MLA/IFA Radiator on + Y Face & 0.110 & Al 6061 \\
\hline Front Panel on -Y Face & 0.096 & Al 6061 \\
\hline 3U Deployable Solar Array Panels (2) without Cells & 0.380 total & FR4 (2.4 mm thick) \\
\hline 1U Solar Array Panel without Cells on -Y Face & 0.050 & FR4 (1.6 mm thick) \\
\hline Solar Array Panel without Cells on -Z Side & 0.025 & FR4 (1.6 mm thick) \\
\hline Cells on 3U Deployable Solar Array Panels & 0.104 total & Silicon Wafer \\
\hline $\begin{array}{c}\text { Cells on Backside of } 3 U \text { Deployable Solar Array } \\
\text { Panels }\end{array}$ & 0.052 total & Silicon Wafer \\
\hline Cells on 2U Solar Array Panels on -Y Side & 0.019 & Silicon Wafer \\
\hline Solar Cell on -Z Side & 0.008 & Silicon Wafer \\
\hline
\end{tabular}


Table 5 and Fig. 11 present the thermophysical properties used in thermal design and analysis of the IceCube.

Table 5. Thermophysical Properties.

\begin{tabular}{|c|c|c|}
\hline Material & Thermal Conductivity $\left(\mathrm{Wm}^{\left.-1{ }^{\circ} \mathrm{C}^{-1}\right)}\right.$ & Specific Heat $\left(\mathrm{kJkg}^{-1}{ }^{\circ}{ }^{-1}\right)$ \\
\hline Aluminum 6061 T-6 & 167 & 0.896 \\
\hline FR-4 Glass-reinforced Polymer & 0.25 & 0.6 \\
\hline Silicon Wafer Cells & 145 & 0.7 \\
\hline PCB $(1 \% \mathrm{Cu})$ & See graph below & 1.6 \\
\hline
\end{tabular}

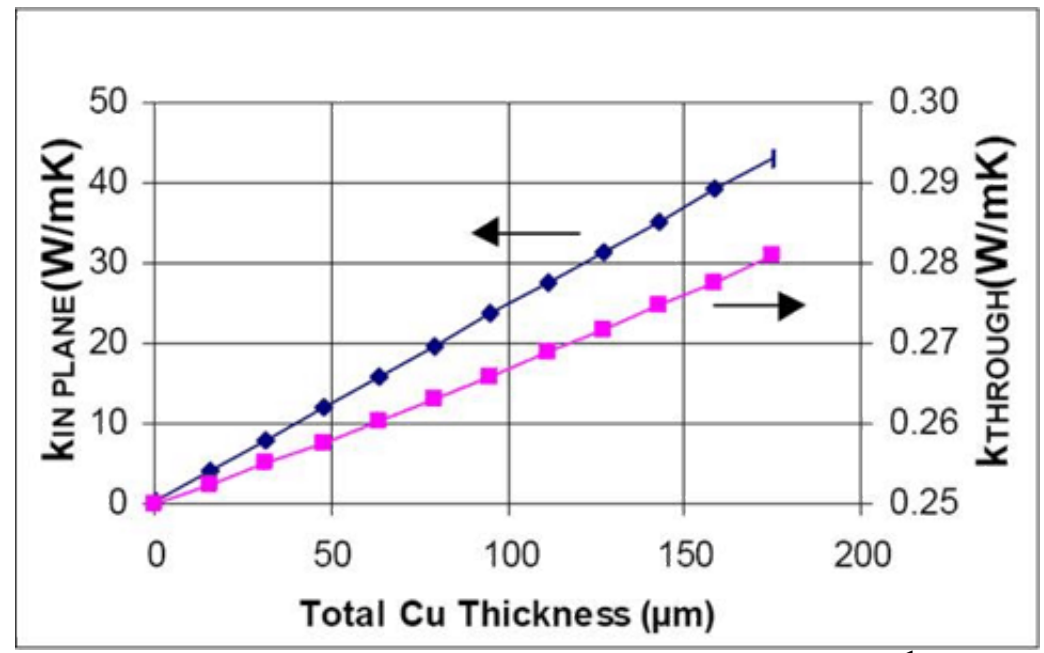

Figure 11. Thermal Conductivity of Circuit Boards. ${ }^{1}$

\section{B. Thermal Isolation}

To meet the temperature and thermal stability requirements of the MLA and IFA of the instrument, the MLA and IFA assembly is thermally isolated from other spacecraft or instrument components. Ultem spacers are used for conductive isolation (Fig. 12), and plated gold or vacuum deposited aluminum (VDA) tape, which has a low emittance, is used for radiative isolation.

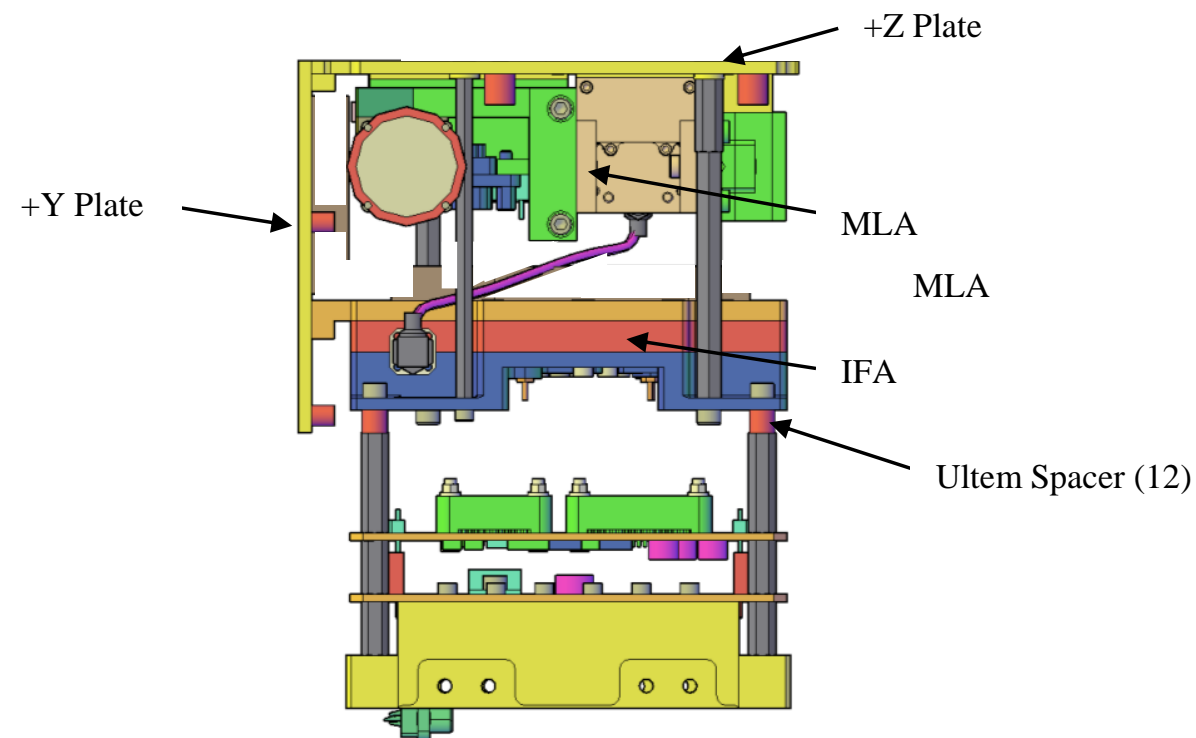

Figure 12. MLA and IFA Thermal Isolation. 


\section{Thermal Radiators for MLA and IFA}

From Table 1, the current best estimates of the power dissipation of the MLA and IFA are $3.07 \mathrm{~W}$ and $1.15 \mathrm{~W}$ respectively. For conservatism, a 15\% uncertainty margin is added to the power dissipation of the MLA, IFA and other instrument components. The top $(+\mathrm{Z})$ plate is used as the MLA radiator and a $+\mathrm{Y}$ plate is used as the IFA radiator (Fig. 12). To minimize the issues with instrument integration, the radiators are separate, instead of an integral unit. The two radiators are bolted together. Indium foil is used as the thermal interface material at the joint to enhance heat conduction. The GSFC SiOx/VDA/Kapton is selected as the thermal coating for the radiators. The ratio of absorptance to emittance of this coating can be tailored by varying the thickness of SiOx.

\section{Thermal Modeling and Analysis}

Fig. 13 and Fig. 14 show the IceCube geometric mathematical model and internal components in the model respectively. Fig. 15 shows the IceCube in orbit animation for $\beta$ angles of $0^{\circ}$ and $+75^{\circ}$. Table 5 and Table 6 present optical properties at the beginning of life (BOL) and end of life (EOL) respectively. Except for the deployable components and surfaces related to deployment of solar array panels, all exterior surfaces of the spacecraft are used as thermal radiators. The GSFC SiOx/Al $\mathrm{O}_{3} / \mathrm{Ag} / \mathrm{Kapton}$ composite coating is used for radiators other than the MLA and IFA radiators. The $\mathrm{SiOx} / \mathrm{VDA} / \mathrm{Kapton}$ and $\mathrm{SiOx} / \mathrm{Al}_{2} \mathrm{O}_{3} / \mathrm{Ag} / \mathrm{Kapton}$ composite thin film coatings can be fabricated in approximately $0.6 \mathrm{~m}$ x $0.6 \mathrm{~m}$ sheets at the GSFC Thin Film Coatings Laboratory. The sheets can be cut into custom sizes and bonded to the IceCube exterior by using a transfer adhesive. The AZ Technology off-the-shelf AZ-93 white paint tape is a backup coating.

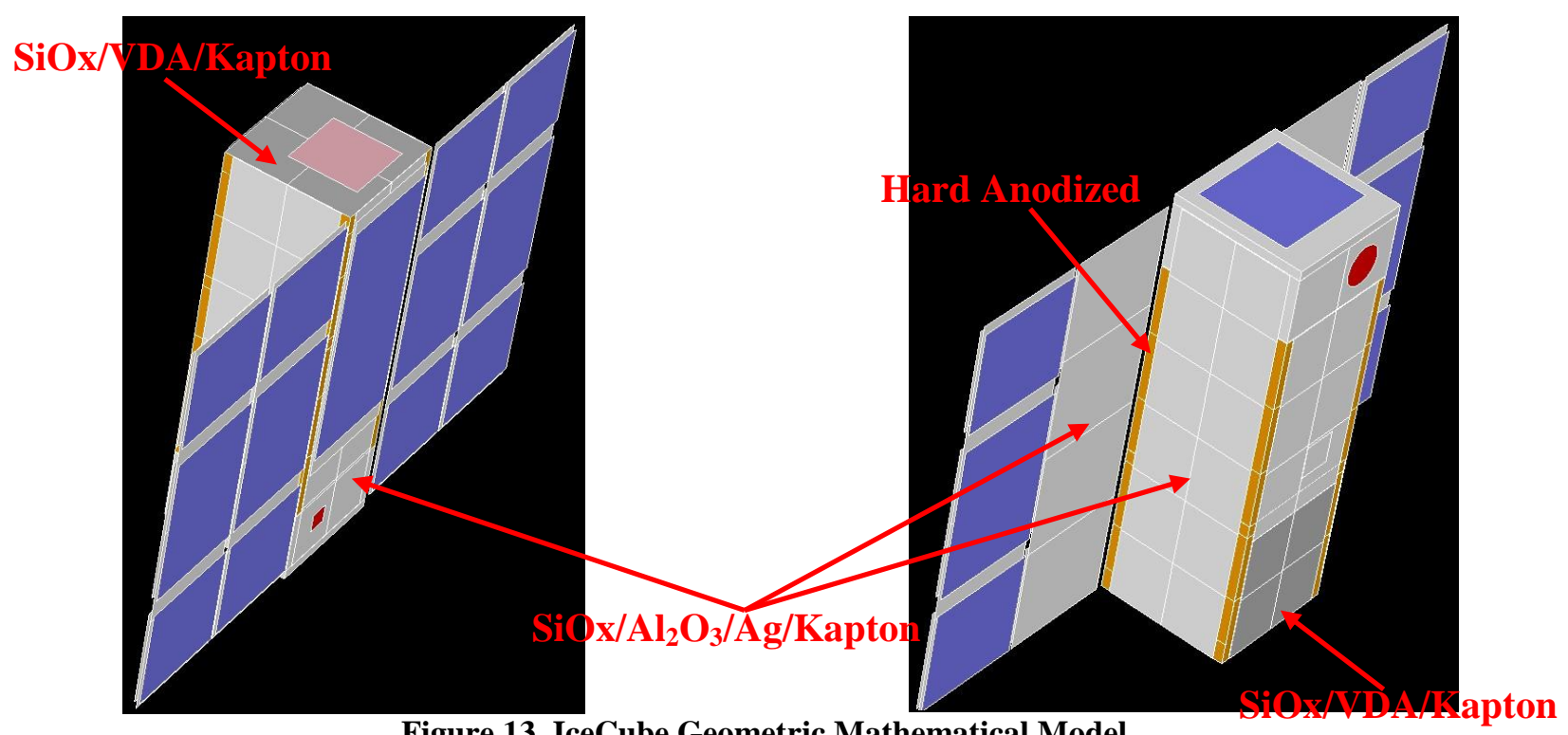

Figure 13. IceCube Geometric Mathematical Model.



Figure 14. Internal Components in Thermal Model.

11

American Institute of Aeronautics and Astronautics 

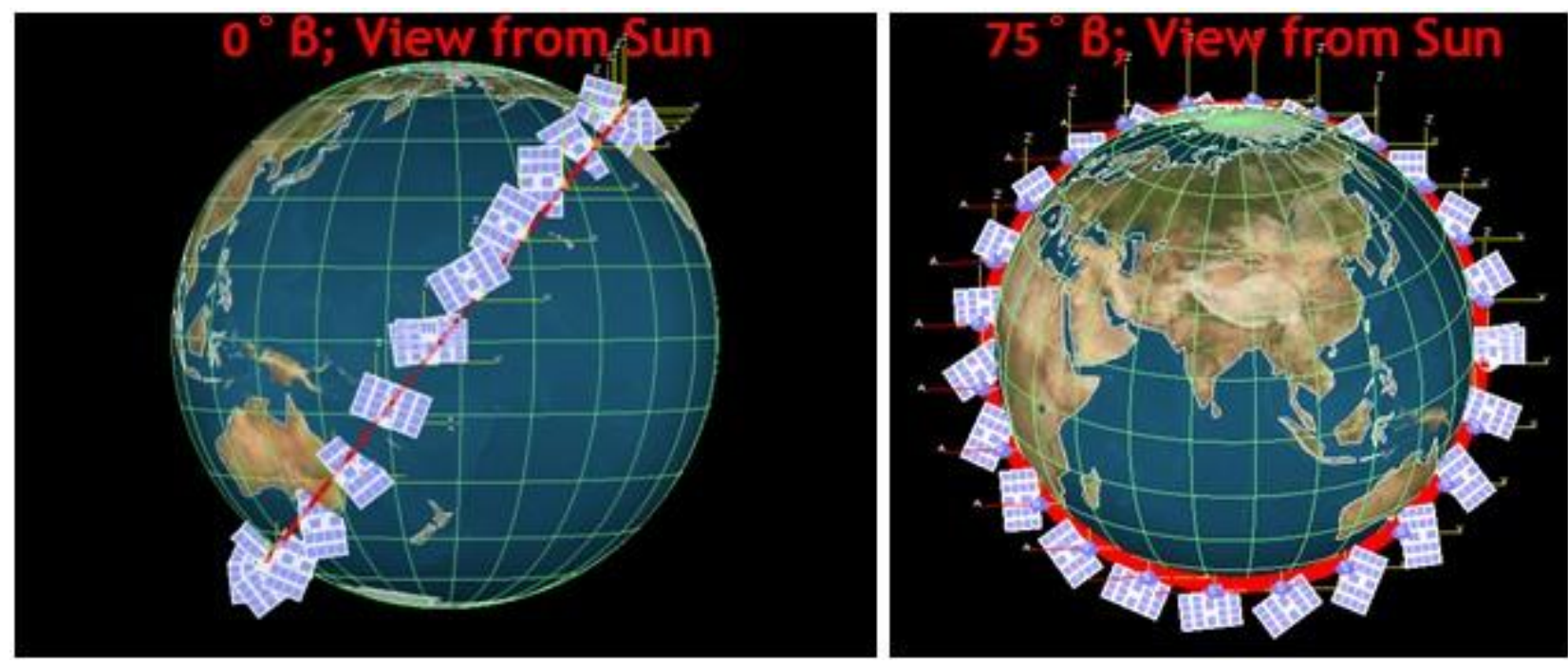

Figure 15. IceCube in Orbit Animation.

Table 5. Optical Properties at BOL.

\begin{tabular}{|c|c|c|c|c|}
\hline & \multicolumn{5}{|c|}{ BOL Cold } \\
\hline Coatings & $\mathbf{a}_{\mathbf{S}}$ & $\mathbf{e}_{\mathbf{H}}$ & $\begin{array}{c}\text { Solar } \\
\text { Specularity }\end{array}$ & IR Specularity \\
\hline $\mathrm{SiOx} / \mathrm{VDA} /$ Kapton & 0.15 & 0.38 & 0.80 & 0.80 \\
\hline $\mathrm{SiOx} / \mathrm{Al}_{2} \mathrm{O}_{3} / \mathrm{Ag} /$ Kapton (Composite) & 0.07 & 0.68 & 0.80 & 0.80 \\
\hline Solar Array Cells & 0.84 & 0.70 & 0.80 & 0.80 \\
\hline Hard Anodized & 0.90 & 0.83 & 0.05 & 0.05 \\
\hline Z306 Black Paint (Internal) & 0.96 & 0.89 & 0.03 & 0.03 \\
\hline Irridited Aluminum & 0.24 & 0.05 & 0.50 & 0.50 \\
\hline AZ-93 White Paint (Tape) & 0.16 & 0.91 & 0.05 & 0.05 \\
\hline
\end{tabular}

Table 6. Optical Properties at EOL.

\begin{tabular}{|c|c|c|c|c|}
\hline & \multicolumn{4}{|c|}{ EOL (<0.5 Year) Hot } \\
\hline Coatings & $\mathbf{a}_{\mathbf{S}}$ & $\mathbf{e}_{\mathbf{H}}$ & $\begin{array}{c}\text { Solar } \\
\text { Specularity }\end{array}$ & IR Specularity \\
\hline $\mathrm{SiOx} / \mathrm{VDA} /$ Kapton & 0.18 & 0.34 & 0.80 & 0.80 \\
\hline $\mathrm{SiOx} / \mathrm{Al}_{2} \mathrm{O}_{3} / \mathrm{Ag} /$ Kapton (Composite) & 0.11 & 0.65 & 0.80 & 0.80 \\
\hline Solar Array Cells & 0.80 & 0.74 & 0.80 & 0.90 \\
\hline Hard Anodized & 0.92 & 0.81 & 0.05 & 0.05 \\
\hline Z306 Black Paint (Internal) & 0.96 & 0.89 & 0.03 & 0.03 \\
\hline Irridited Aluminum & 0.28 & 0.05 & 0.50 & 0.50 \\
\hline $\mathrm{AZ}-93$ White Paint (Tape) & 0.18 & 0.89 & 0.05 & 0.05 \\
\hline
\end{tabular}

Fig. 16 and Fig. 17 present the worst hot case temperature predictions for the MLA and IFA at $0^{\circ} \beta$ angle and $+75^{\circ} \beta$ angle respectively. The temperature instability is as much as $\pm 7^{\circ} \mathrm{C}$. It far exceeds the requirement. 




-MLA —IFA

Figure 16. Worst Hot Case Temperature Predictions for MLA and IFA at $0^{\circ} \beta$.

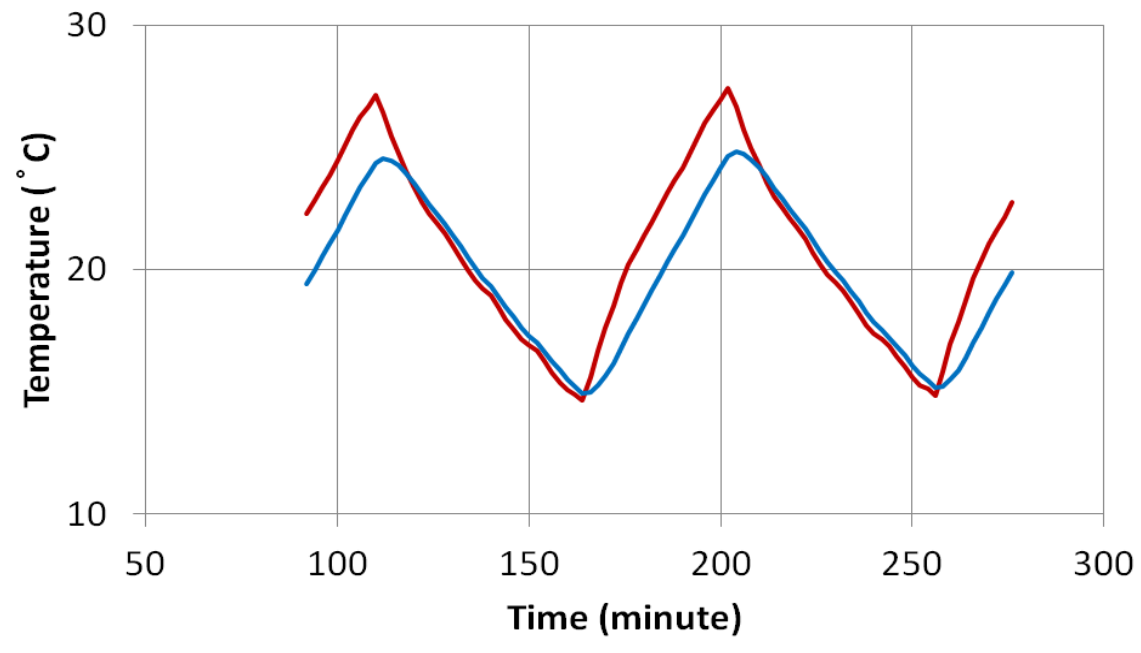

-MLA -IFA

Figure 17. Worst Hot Case Temperature Predictions for MLA and IFA at $75^{\circ} \beta$.

\section{E. Paraffin PCM for Thermal Energy Storage}

Mini paraffin PCM packs are used to meet the MLA and IFA temperature and thermal stability requirements. They are attached to the exterior of the top $(+Z)$ plate, interior of the $+Y$ plate, and the top of the IFA lid (Fig.18 and Fig. 19). Therefore they are thermally coupled by the $+Z$ plate and $+Y$ plate. The mini paraffin packs consist of a fine pore aluminum honeycomb core embedded with K1100 carbon fibers, aluminum 6061-T6 frame, aluminum 1100-H19 facesheets and paraffin. 




Figure 18. Mini Paraffin Packs for MLA and IFA.


Figure 19. Mini Paraffin Packs.

Fig. 20 shows the heat paths for the MLA and IFA. The MLA and IFA waste heat and environmental heating by Earth flux increase the paraffin pack contact surface temperature to the melting point of paraffin. A liquid-solid phase front propagates outward from the contact surface (Fig. 21). The temperature of the contact surface equilibrates at the melting point of paraffin. Note that the phase front stops unless heat is added or removed. When the MLA and IFA stop dissipating heat (i.e., are powered off), the paraffin packs lose heat to the radiators by conduction through the surface contact. As a result, the phase front recedes. Fig. 22 illustrates the paraffin melt and freeze cycle in each orbit. The MLA or IFA temperature is approximately $2^{\circ} \mathrm{C}$ warmer than the melting point of paraffin due to the thermal resistance between the MLA or IFA and paraffin pack contact surface.

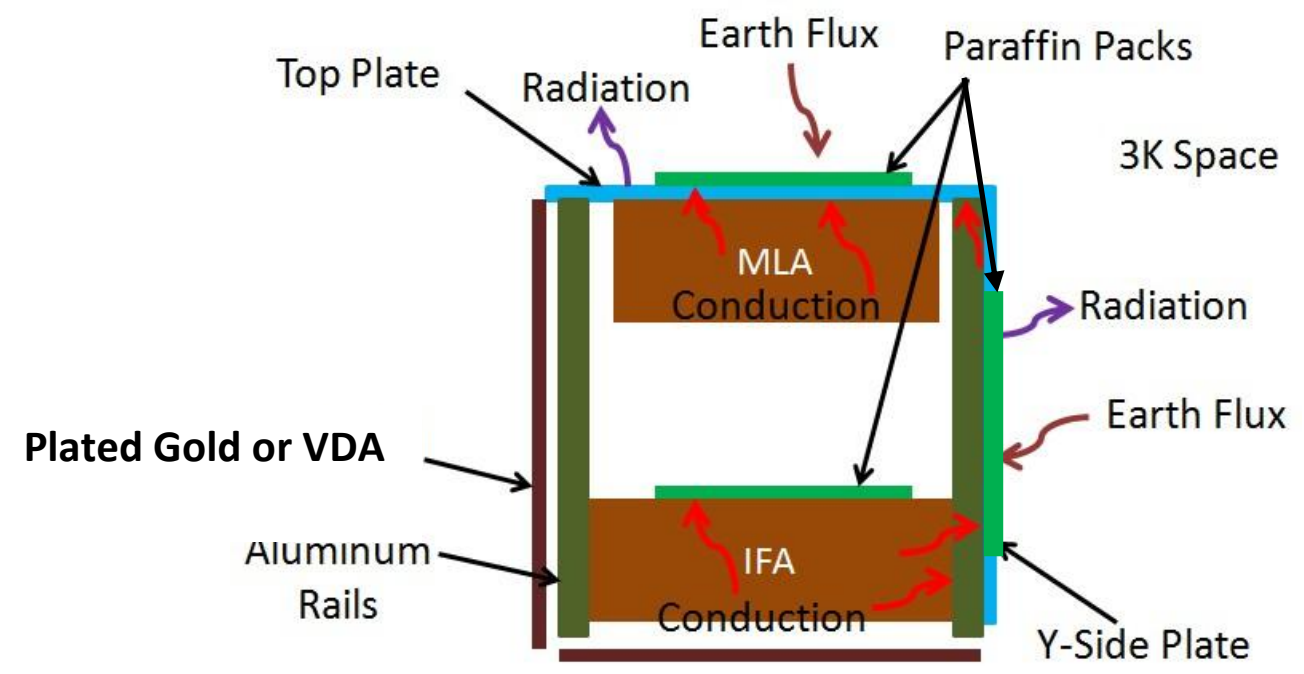

Figure 20. MLA and IFA Heat Transfer. 


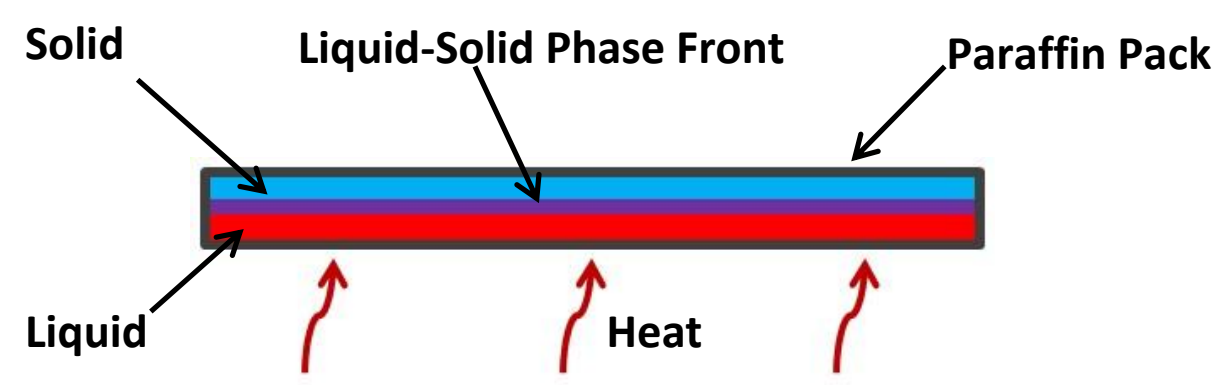

Figure 21 Solid-Liquid Phase Front in Paraffin Pack.

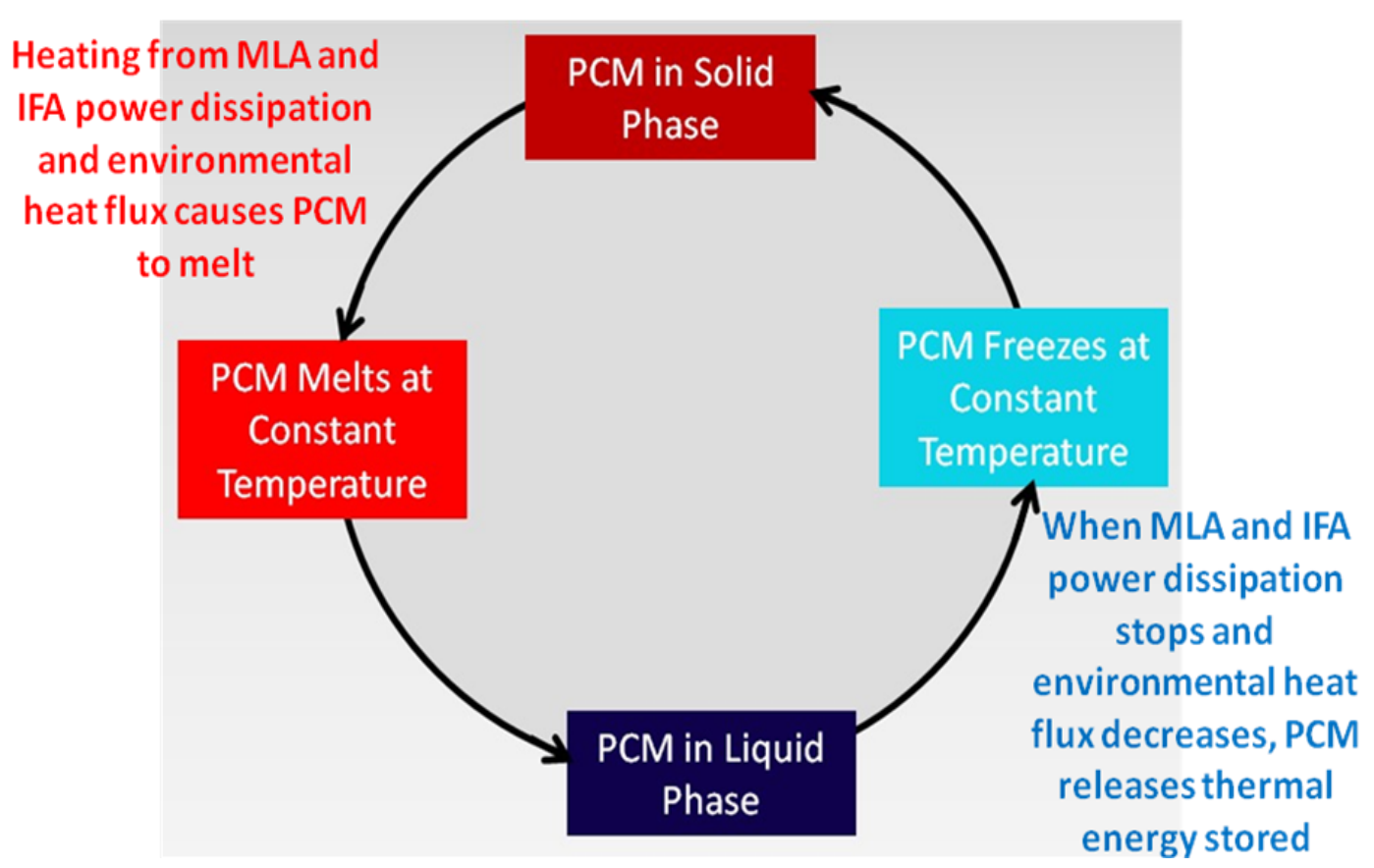

Figure 22. Paraffin Melt and Freeze Cycle.

Fig. 23 and Fig. 24 show the melting point and enthalpy of fusion as a function of the paraffin carbon number respectively..$^{2-4}$ To meet the $20^{\circ} \mathrm{C}$ MLA and IFA temperature requirement and to maximize the enthalpy of fusion, $\mathrm{n}$ hexadecane $\left(\mathrm{C}_{16} \mathrm{H}_{34}\right)$, which has a carbon number of 16 , is selected. Its melting point is $18.2^{\circ} \mathrm{C}$ and its enthalpy of fusion is $237 \mathrm{~kJ} / \mathrm{kg}$. 


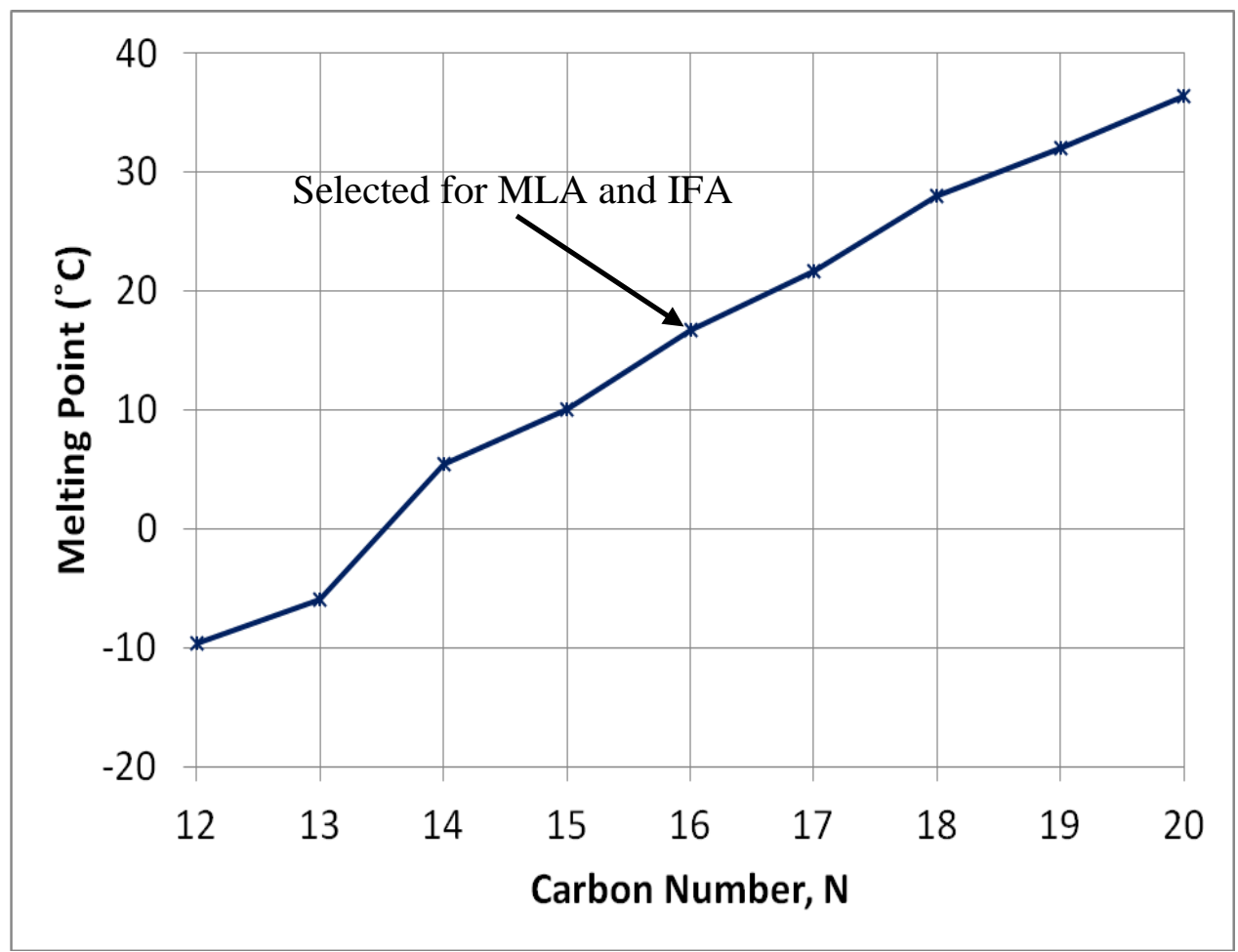

Figure 23. Melting Point of Paraffin $\left(\mathrm{C}_{\mathrm{N}} \mathrm{H}_{2 \mathrm{~N}+2}\right)$.

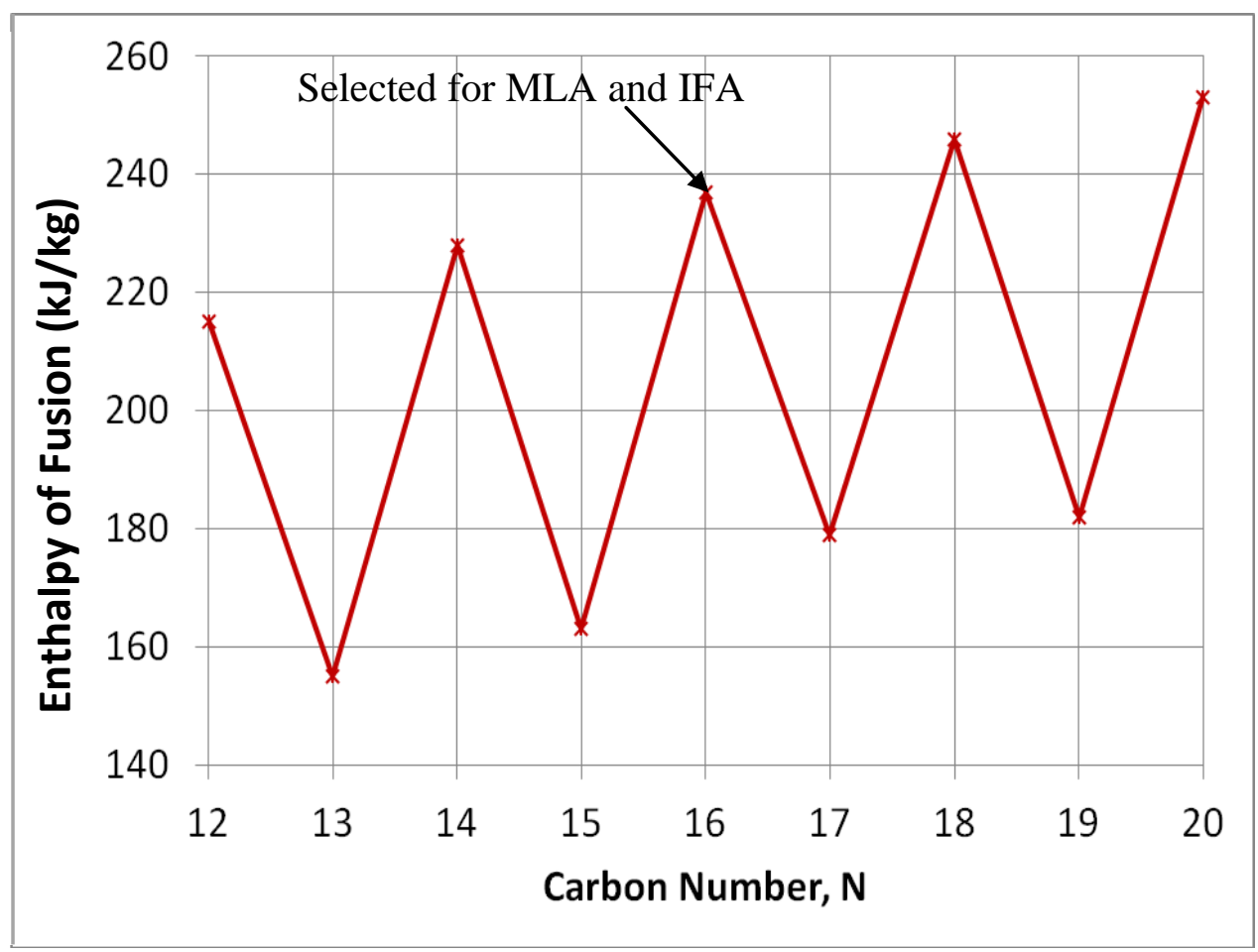

Figure 24. Enthalpy of Fusion of Paraffin $\left(\mathrm{C}_{\mathrm{N}} \mathrm{H}_{2 \mathrm{~N}+2}\right)$.

Fig. 25 presents the heat load on the MLA and IFA assembly at a $0^{\circ} \beta$ angle. Fig. 26 presents the thermal energy stored in the MLA and IFA assembly at a $0^{\circ} \beta$ angle. With $31 \mathrm{~g}$ of n-hexadecane, it can store $7.35 \mathrm{~kJ}$ as latent heat. The MLA and IFA are powered on for 32.3 minutes continuously per orbit in the sunlight to melt the paraffin. Fig. 27 presents the heat load on the MLA and IFA assembly at a $+75^{\circ} \beta$ angle. Fig. 28 presents the thermal energy 
stored in the MLA and IFA assembly at a $+75^{\circ} \beta$ angle. There is no eclipse at this $\beta$ angle. With $31 \mathrm{~g}$ of $\mathrm{n}$ hexadecane, it can store $7.35 \mathrm{~kJ}$ as latent heat. The MLA and IFA are powered on for 38 minutes continuously per orbit. The same is true for $-75^{\circ} \beta$ angle. The Earth flux absorbed by the $+\mathrm{Z}$ and $+\mathrm{Y}$ radiators decreases as the absolute value of the $\beta$ angle increases. Therefore the MLA and IFA turn-on time is increased as the absolute value of the $\beta$ angle increases so that the thermal energy stored in the paraffin in sunlight is the same. Fig. 29 presents the MLA and IFA turn-on time versus the $\beta$ angle.

When the MLA and IFA are turned off, the radiators ( $+\mathrm{Z}$ plate and $+\mathrm{Y}$ plate) continue radiating heat to $3 \mathrm{~K}$ space, and the paraffin begins to freeze. The liquid-solid phase change front recedes. After losing $7.35 \mathrm{~kJ}$, the paraffin is all frozen. The melt and freeze cycle of paraffin continues in each orbit. Fig. 30 shows the temperature predictions for the MLA and IFA.

Note that under-sizing the mass of paraffin will cause over melting, which leads to temperature perturbation because sensible heat storage instead of latent heat storage occurs. Per NASA GSFC Gold Rule, $40.3 \mathrm{~g}$ of $\mathrm{n}$ hexadecane is used so that it provides a $30 \%$ margin for phase change thermal energy storage. It minimizes the probability that the paraffin is entirely melted.

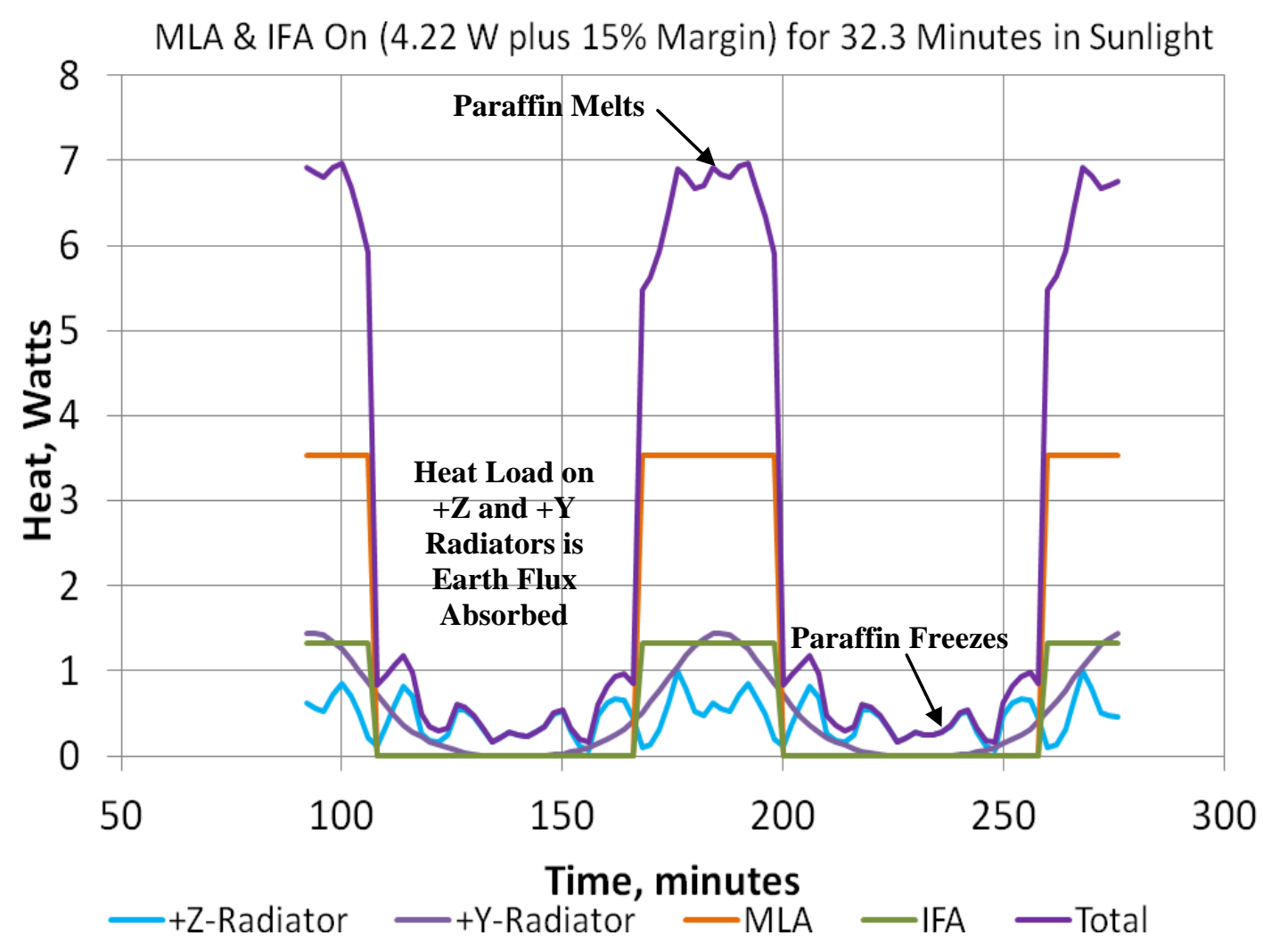

Figure 25. MLA and IFA Assembly Heat Load at $0^{\circ} \beta$. 




Figure 26. Heat Stored in MLA and IFA Assembly with $31 \mathrm{~g}$ of n-Hexadecane at $0^{\circ} \beta$.


Figure 27. MLA and IFA Assembly Heat Load at $75^{\circ} \beta$. 


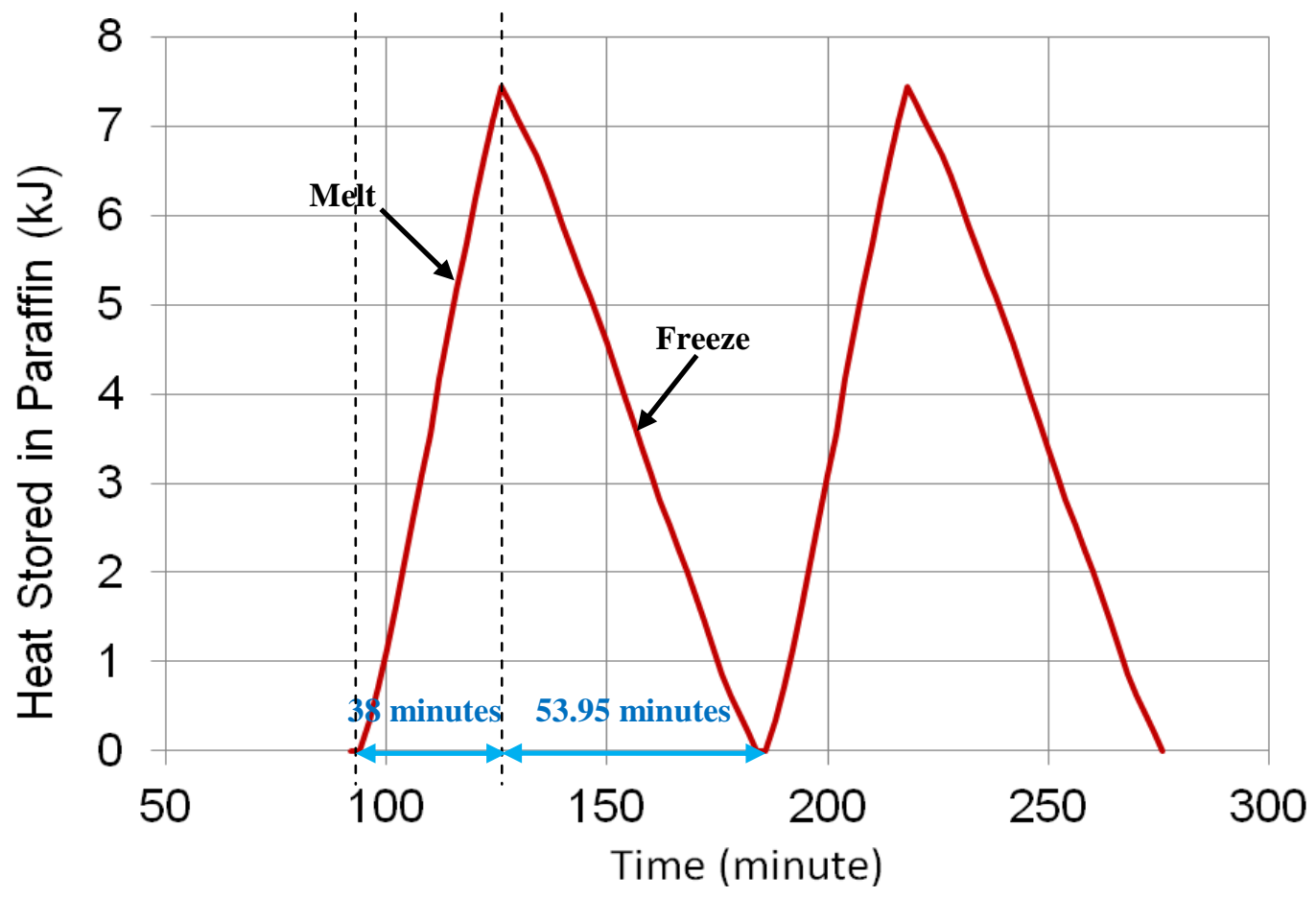

Figure 28. Heat Stored in MLA and IFA Assembly with $31 \mathrm{~g}$ of n-Hexadecane at $75^{\circ} \mathrm{\beta}$.

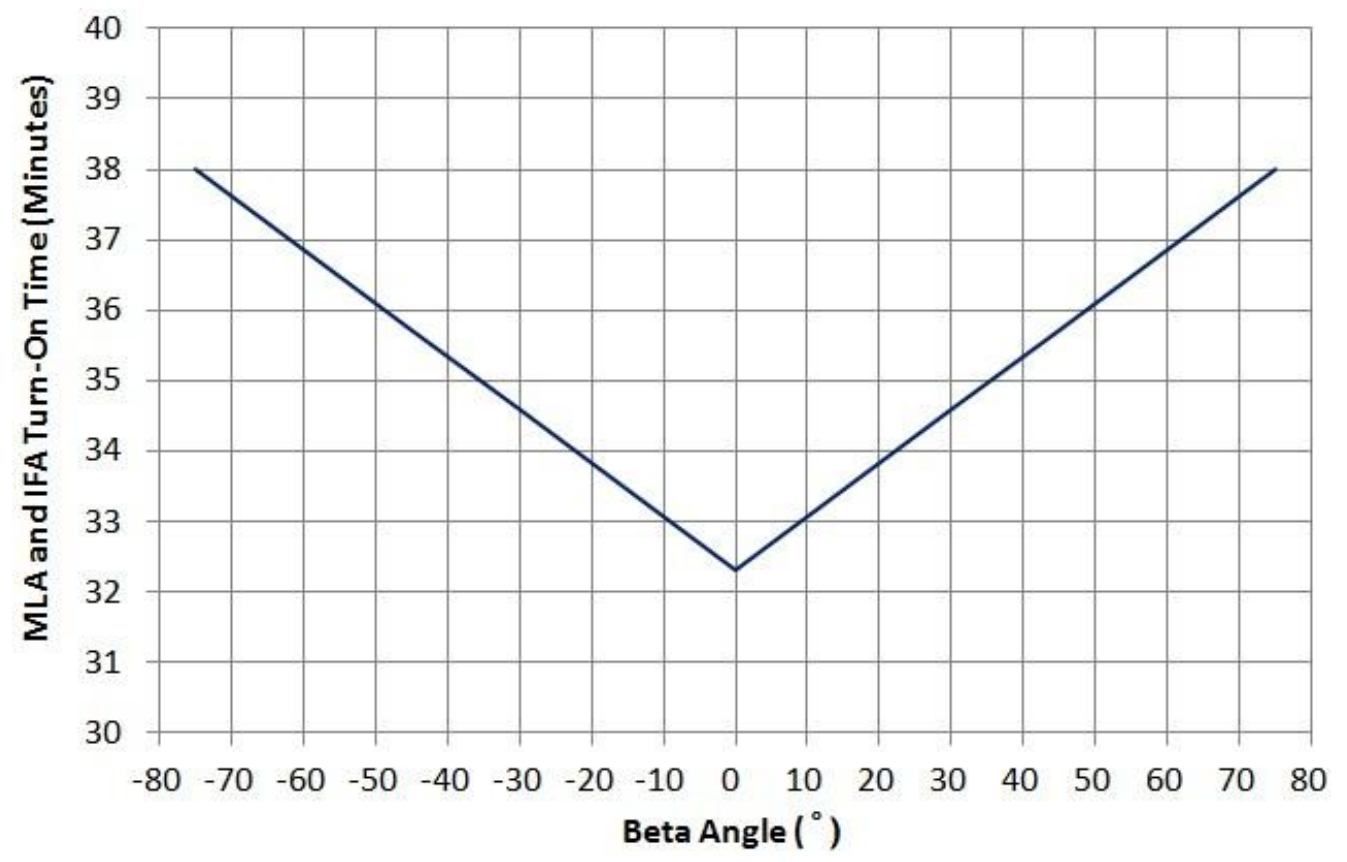

Figure 29. MLA and IFA Turn-On Time Required for Melting Paraffin. 


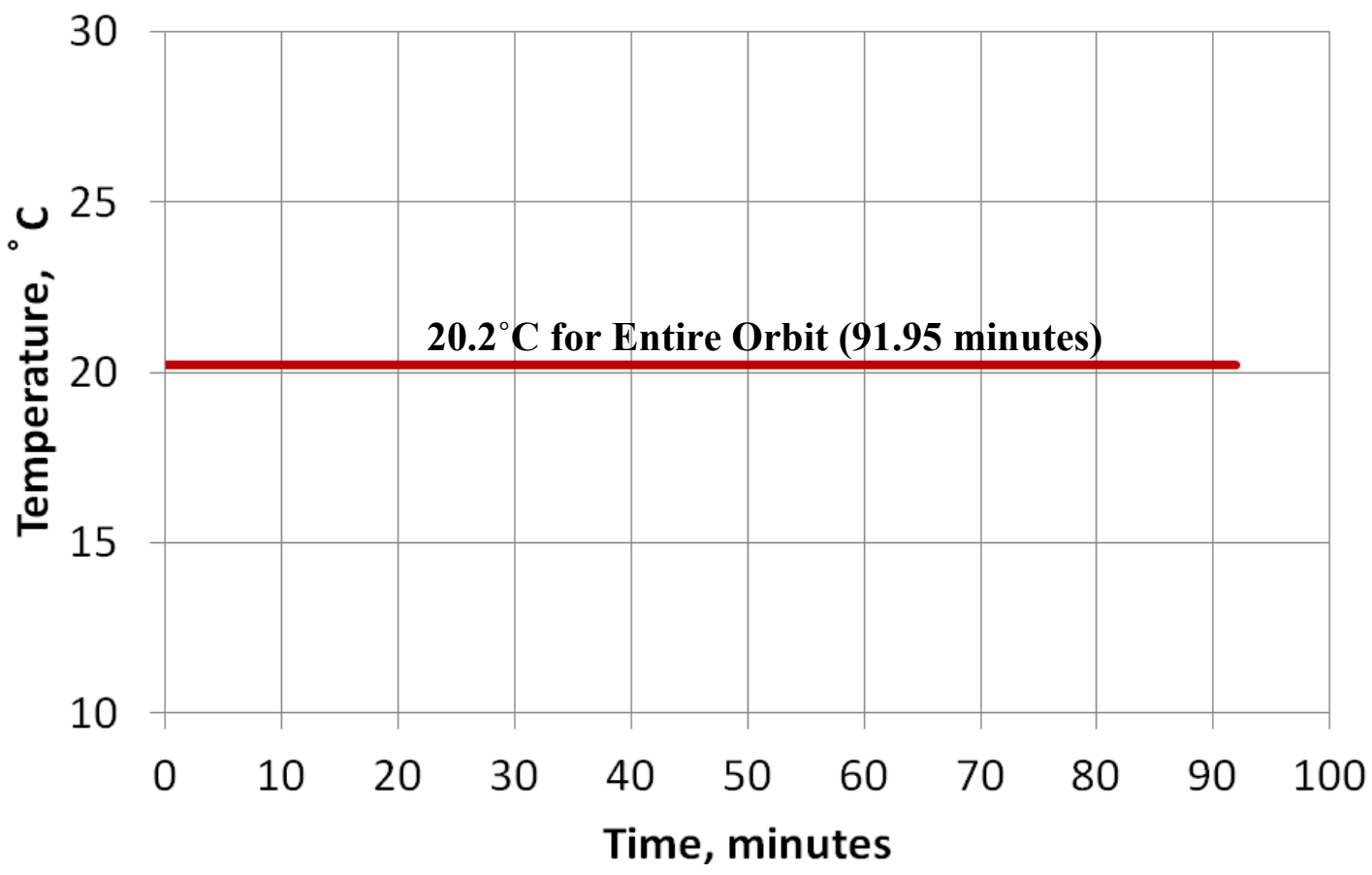

Figure 30. MLA and IFA Temperature Predictions for All $\beta$ Angles.

The liquid density of $n$-hexadecane is used because it is less than the solid density. Fig. 31 shows the liquid density as a function of temperature. ${ }^{9}$ Note that $70^{\circ} \mathrm{C}$ is the fill temperature being planned. The volume of $\mathrm{n}$ hexadecane required is calculated to be $54.5 \mathrm{~cm}^{3}$ based on the $31 \mathrm{~g}$ mass required plus a $30 \%$ margin and its liquid density of $0.739 \mathrm{~g} \mathrm{~cm}^{-3}$ at $70^{\circ} \mathrm{C}$.

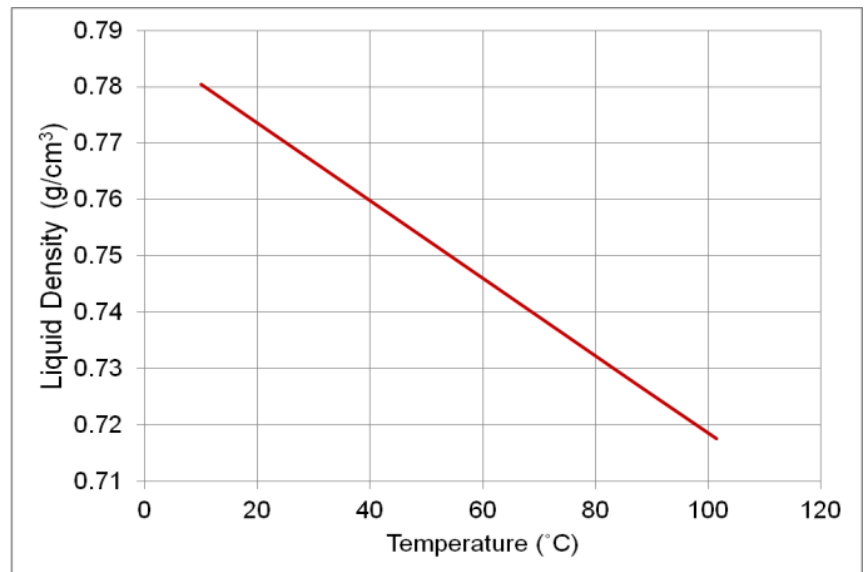

Figure 31. n-Hexadecane Liquid Density versus Temperature.

From the $25.4 \mathrm{~cm} \times 25.4 \mathrm{~cm} \times 1.016 \mathrm{~cm}$ n-hexadecane panels built for the GSFC Vegetation Canopy Lidar (VCL) project ${ }^{3}$, the ratio of mass of paraffin to mass of aluminum structure and K1100 fiber/aluminum core is 1.51:1. The volumetric packing fraction of paraffin is $87 \%$. The VCL paraffin panels were attached to an aluminum substrate by using Nusil, and therefore had no mounting holes. The mini paraffin packs for the IceCube are much smaller in size and have a total of thirteen mounting holes (Fig. 19). The mounting holes reduce the usable paraffin volume by approximately $5 \%$. A $75 \%$ volumetric packing fraction for paraffin is deemed conservative. Therefore the volume of $n$-hexadecane packs required is calculated to be $73 \mathrm{~cm}^{3}$. The volumes of the three mini paraffin packs 
for the top $(+\mathrm{Z})$ plate, $+\mathrm{Y}$ plate and IFA lid are $23.6 \mathrm{~cm}^{3}, 22.3 \mathrm{~cm}^{3}$ and $27.9 \mathrm{~cm}^{3}$ respectively. They add up to 73.8 $\mathrm{cm}^{3}$. Mechanical packaging to accommodate them drives the dimensions and geometry. The volume of the paraffin and internal core is $61.8 \mathrm{~cm}^{3}$. The volumetric packing fraction of paraffin is expected to be at least $88 \%$. Therefore the volume of paraffin is expected to be at least $54.5 \mathrm{~cm}^{3}$. The mini paraffin packs are attached to the top (+Z) plate, $+Y$ plate and IFA lid by \#2-56 fasteners. Indium foil is used as the thermal interface material to enhance heat conduction at the joints. Kapton tape is also used to tie the sides of the packs to the top $(+Z)$ plate, $+Y$ plate and IFA lid to add contact pressure.

\section{Paraffin PCM Flight Heritage}

Two small paraffin packs (Fig. 32) are flown on the NASA MESSENGER Mercury Dual Imaging System (MDIS) instrument. ${ }^{3}$ The paraffin is dodecane $\left(\mathrm{C}_{12} \mathrm{H}_{26}\right)$. Paraffin panels (Fig. 33) were built for the GSFC VCL project. ${ }^{3}$ The paraffin is n-hexadecane $\left(\mathrm{C}_{16} \mathrm{H}_{34}\right)$, which is also used on the IceCube. There was no degradation after 5,000 thermal vacuum cycles. For the IceCube mission, the number of melt and freeze cycles is 470 . The technology readiness level (TRL) of paraffin phase change material is at least 7.

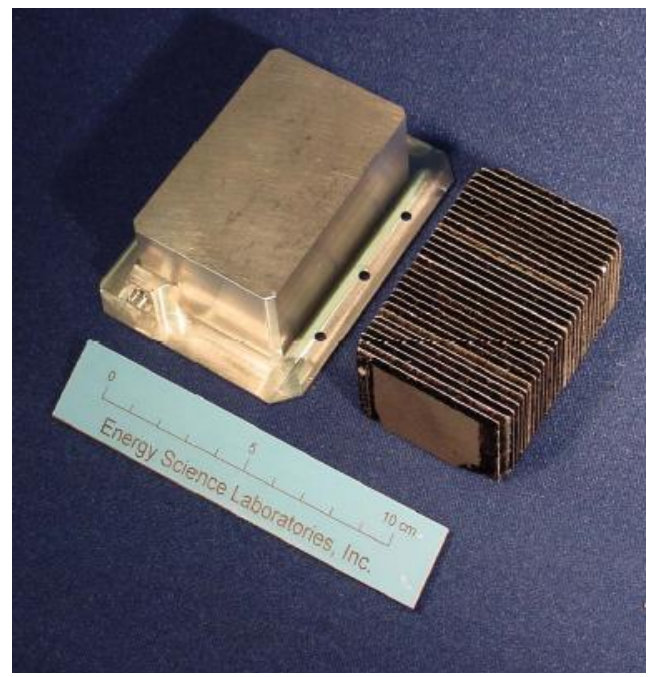

Figure 32. Paraffin Pack Flown on MESSENGER MDIS $\left(\sim 7 \mathrm{~cm} x \sim 5 \mathrm{~cm}\right.$ Footprint). ${ }^{3}$

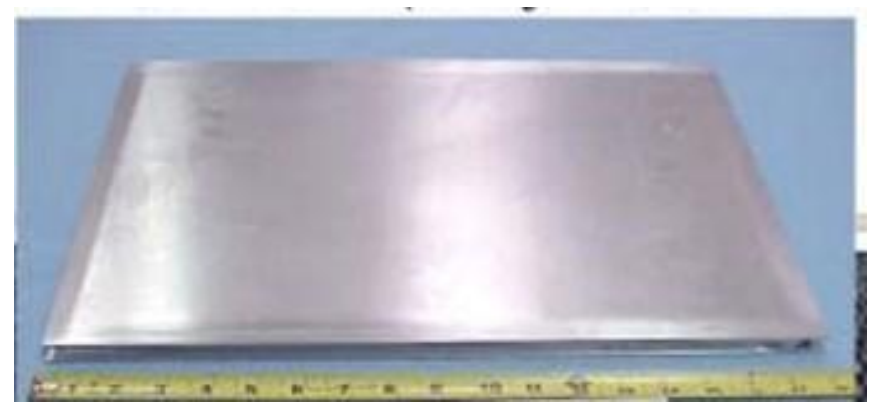

Figure 33. Paraffin Panel $(25.4 \mathrm{~cm} \times 25.4 \mathrm{~cm} \times 1 \mathrm{~cm})$ for NASA VCL Project. ${ }^{3}$

\section{Conclusion}

The MLA and IFA of the instrument on the IceCube require a $20^{\circ} \mathrm{C}$ temperature and a thermal stability of $\pm 1^{\circ} \mathrm{C}$. The thermal environment of the ISS orbit for the IceCube is very unstable due to solar $\beta$ angles in the $-75^{\circ}$ to $+75^{\circ}$ range, which has an eclipse time from 0 to 36.3 minutes. Additionally the instrument is powered off in every eclipse to conserve electrical power. These two thermal penalties cause thermal stability to the MLA and IFA. Mini paraffin PCM packs are used to meet the temperature and thermal stability requirements of these instrument components. Also these components are thermally isolated from the spacecraft and other instrument components, and have their own radiators. With a $31 \mathrm{~g}$ mass plus a $30 \%$ margin of n-hexadecane, the MLA and IFA are powered on for 32.3 minutes in sunlight at a $0^{\circ} \beta$ angle to melt the paraffin. As the absolute value of the $\beta$ angle increases, the Earth flux 
absorbed by the MLA and IFA radiators decreases so that the MLA and IFA are powered on longer. The MLA and IFA are powered on for 38 minutes in sunlight at a $75^{\circ}$ ( + or -) $\beta$ angle to melt the paraffin. When the MLA and IFA are powered off, their radiators continue to radiate heat to $3 \mathrm{~K}$ space and the paraffin freezes. The melt and freeze cycle repeats in each orbit. The $30 \%$ mass margin for the paraffin minimizes the probability that the paraffin is over melted.

\section{References}

Berry, G., "Thermal Management Considerations for PCBs: Measurement techniques and heat conduction", http://www.tak2000.com/data/PCB_Thermal_Considerations.

Knowles, T. R., "PCM Thermal Control of Nickel-Hydrogen Batteries", PL-TR--93-1075, Phillips Laboratory, Kirtland Air Force Base, NM, June 1993.

Knowles, T. R., "Phase Change Composite Thermal Energy Storage", Energy Science Laboratories, Inc., San Diego, CA, Sept. 2007.

Kedl, R. J., "Wallboard with Latent Heat Storage for Passive Solar Applications", ORNLTM-11541, Oak Ridge National Laboratory, Oak Ridge, TN, May 1991.

${ }^{5}$ Lewis, R.J., Sr (Ed.), Hawley's Condensed Chemical Dictionary, $12^{\text {th }}$ ed., New York, NY: Van Nostrand Rheinhold Co., p. 596, 1993.

${ }^{6}$ Hale, D.V., et al., Phase Change Materials Handbook, NASA-CR-61363, 1971.

${ }^{7}$ Humphries, W.R., and Griggs, E.I., A Design Handbook for Phase Change Thermal Control and Energy Storage Devices, NASA-TP-1074, 1977.

${ }_{9}^{8}$ Poling, P. E., et al., Perry's Chemical Engineers' Handbook $8^{\text {th }}$ ed., McGraw-Hill, New York, 2008.

${ }^{9}$ Saturated Liquid Density Calculation by DIPPR105 Equation, http://ddbonline.ddbst.de/DIPPR105DensityCalculation/DIPPR105CalculationCGI.exe?component=Hexadecane. 